\title{
Kinetics of Reactions of the Actinomadura R39 DD-Peptidase with Specific Substrates ${ }^{\dagger}$
}

\author{
S. A. Adediran, ${ }^{\ddagger}$ Ish Kumar, ${ }^{+\|}$Rajesh Nagarajan, ${ }^{\star \perp}$ Eric Sauvage, ${ }^{\S}$ and R. F. Pratt*, \\ *Department of Chemistry, Wesleyan University, Lawn Avenue, Middletown, Connecticut 06459, United States, and \\ ${ }^{\S}$ Centre d'Ingéniere des Proteines, Université de Liège, B-4000 Sart Tilman, Liège, Belgium. "Present address: School of \\ Natural Sciences, Fairleigh Dickinson University, Teaneck, NJ 07666. ${ }^{\perp}$ Present address: Department of \\ Chemistry and Biochemistry, Boise State University, 1910 University Drive, Boise, ID 83725-1520
}

Received November 2, 2010; Revised Manuscript Received December 6, 2010

\begin{abstract}
The Actinomadura R39 DD-peptidase catalyzes the hydrolysis and aminolysis of a number of small peptides and depsipeptides. Details of its substrate specificity and the nature of its in vivo substrate are not, however, well understood. This paper describes the interactions of the R39 enzyme with two peptidoglycan-mimetic substrates 3-(D-cysteinyl)propanoyl-D-alanyl-D-alanine and 3-(D-cysteinyl)propanoyl-D-alanyl-D-thiolactate. A detailed study of the reactions of the former substrate, catalyzed by the enzyme, showed DD-carboxypeptidase, DD-transpeptidase, and DD-endopeptidase activities. These results confirm the specificity of the enzyme for a free D-amino acid at the N-terminus of good substrates and indicated a preference for extended D-amino acid leaving groups. The latter was supported by determination of the structural specificity of amine nucleophiles for the acyl-enzyme generated by reaction of the enzyme with the thiolactate substrate. It was concluded that a specific substrate for this enzyme, and possibly the in vivo substrate, may consist of a partly cross-linked peptidoglycan polymer where a free side chain N-terminal un-cross-linked amino acid serves as the specific acyl group in an endopeptidase reaction. The enzyme is most likely a DD-endopeptidase in vivo. $\mathrm{pH}$-rate profiles for reactions of the enzyme with peptides, the thiolactate named above, and $\beta$-lactams indicated the presence of complex proton dissociation pathways with sticky substrates and/or protons. The local structure of the active site may differ significantly for reactions of peptides and $\beta$-lactams. Solvent kinetic deuterium isotope effects indicate the presence of classical general acid/base catalysis in both acylation and deacylation; there is no evidence of the low fractionation factor active site hydrogen found previously in class $\mathrm{A}$ and $\mathrm{C} \beta$-lactamases.
\end{abstract}

The DD-peptidases represent a family of enzymes that catalyze the final steps in bacterial cell wall biosynthesis. Their substrates are peptide elements of peptidoglycan. They catalyze nucleophilic double displacement reactions at $N$-acyl-DD-dipeptide moieties leading, via formation of an acyl-enzyme intermediate, to carboxypeptidase, endopeptidase, and transpeptidase reactions (Scheme 1).

The latter of these reactions leads to the cross-linking of peptidoglycan to form the final mature polymer while the former two are believed to be important in control of the degree of crosslinking $(1,2)$. These reactions are clearly important to bacteria, but they are also important to people since the enzymes catalyzing them, being unique to bacteria, represent excellent targets for antibacterial drugs. The best known of the latter are of course the $\beta$-lactams, which inhibit DD-peptidases by formation of stable acyl-enzymes $(3,4)$. The increasing resistance displayed by

\footnotetext{
This research was supported by National Institutes of Health Grant AI-17986 (R.F.P.) and in part by the Belgian Program on Interuniversity Poles of Attraction initiated by the Belgian State, Prime Minister's Office, Science Policy programming (IAP no. P6/19), the Fonds de la Recherche Scientifique (IISN4.4505.00, IISN4.4509.09, FRFC2.4.508.01.F, FRFC9.4.538.03.F, FRFC2.4.524.03), and the University of Liège (Fonds spéciaux, Crédit classique, 2009).

*Corresponding author: telephone, 860-685-2629; e-mail, rpratt@ wesleyan.edu; fax, 860-685-2211.
}

bacteria to all antibiotics, including $\beta$-lactams, encourages further research on the relevant targets $(5,6)$.

The DD-peptidases have been classified into groups based on molecular mass and amino acid homology $(7,8)$. One important division is between the high molecular mass $(\mathrm{HMM})^{1}$ enzymes, usually $60-90 \mathrm{kDa}$, and low, of molecular mass less than $50 \mathrm{kDa}$ (LMM). The former enzymes are believed to act as transpeptidases in vivo while the latter are carboxypeptidases and endopeptidases $(1,2)$. The HMM group can be subdivided into classes A and B and the LMM group into classes A, B, and $\mathrm{C}$, again based on amino acid sequence homology $(7,8)$. Curiously, the former enzymes, in vitro, do not catalyze, at any significant rate, the cleavage of small, peptidoglycan-mimetic peptides (9). The reasons for this are not known. The LMM group generally does catalyze the hydrolysis and aminolysis of such peptides and, in certain cases at least (see

\footnotetext{
${ }^{1}$ Abbreviations: AMPSO, 3-[(1,1-dimethyl-2-hydroxyethyl)amino]-2hydroxypropanesulfonic acid; CAPS, 3-(cyclohexylamino)-1-propanesulfonic acid; DMSO, dimethyl sulfoxide; ESMS, electrospray mass spectrometry; HMM, high molecular mass; LMM, low molecular mass; MES, 2-( $N$-morpholino)ethanesulfonic acid; MOPS, 3-( $N$-morpholino)propanesulfonic acid; NMR, nuclear magnetic resonance; TAPS, 3-[[tris(hydroxymethyl)methyl]amino]-1-propanesulfonic acid; TFA, trifluoroacetic acid; THF, tetrahydrofuran.
} 
Scheme 1

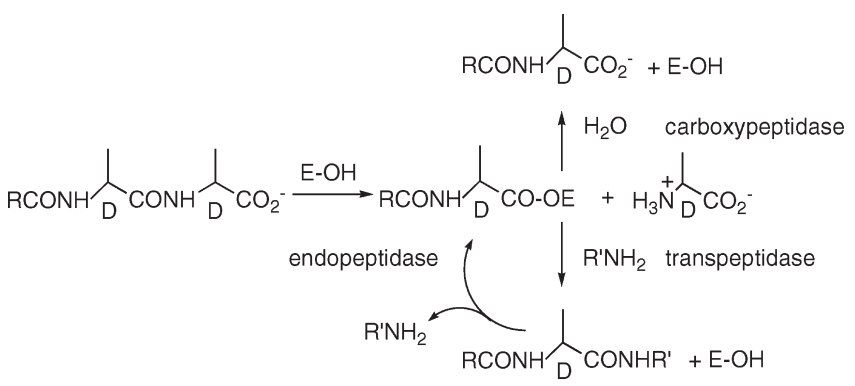

below), shows dramatic specificity for elements of peptidoglycan structure.

One very well studied example of these enzymes, and one showing pronounced substrate specificity, is the class B LMM DD-peptidase of Streptomyces R61. The stem peptide of this organism has the structure 1. It has been demonstrated that the peptide $\mathbf{2}$ is a very specific substrate of this enzyme $\left(k_{\text {cat }} / K_{\mathrm{m}}=8.7 \times 10^{6} \mathrm{~s}^{-1} \mathrm{M}^{-1}\right)(10)$. On the other hand, the peptide 3 is quite a poor substrate $\left(k_{\mathrm{cat}} / K_{\mathrm{m}}=\right.$ $\left.270 \mathrm{~s}^{-1} \mathrm{M}^{-1}\right)$ (11). This enzyme, therefore, appears to specifically recognize the free side chain $\mathrm{N}$-terminus of the stem peptide in choosing a substrate. The structural basis for this specificity has been clearly demonstrated by crystal structures of the R61 DD-peptidase in complexes with a peptide, a phosphonate inhibitor, and a $\beta$-lactam, each bearing the specific side chain of $2(12-14)$. In another example, 4 is an excellent substrate $\left(k_{\text {cat }} / K_{\mathrm{m}}=5.6 \times 10^{6} \mathrm{~s}^{-1} \mathrm{M}^{-1}\right)$ of the DD-peptidase of Actinomadura R39, a LMM class C enzyme, again mimicking the free side chain $\mathrm{N}$-terminus of the relevant stem peptide $\mathbf{5}$, while $\mathbf{3}$ is a relatively poor substrate $\left(k_{\text {cat }} /\right.$ $\left.K_{\mathrm{m}}=2.9 \times 10^{3} \mathrm{~s}^{-1} \mathrm{M}^{-1}\right)(11)$. Here also the structural basis of the specificity has been demonstrated crystallographically $(15,16)$.
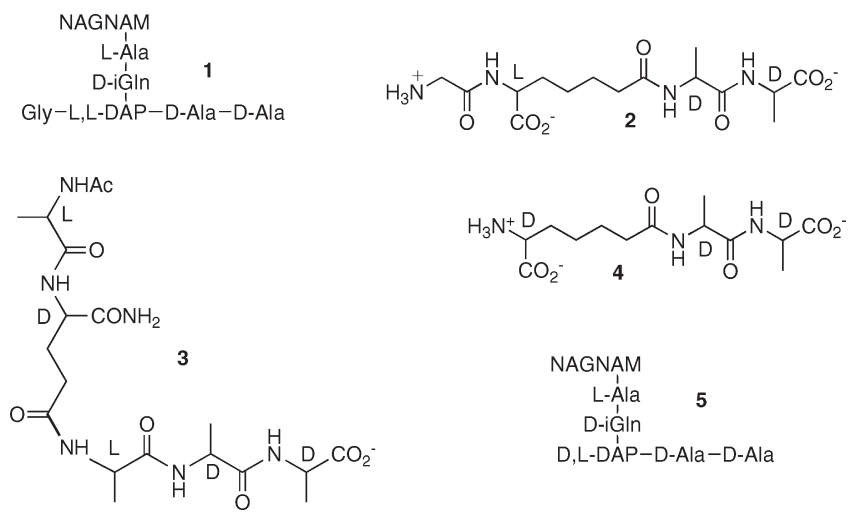

Although the Liège group has studied various aspects of the R39 enzyme quite extensively over many years (17-20), a systematic study of its reaction with specific substrates has not been made. This is important since the active site of the R39 enzyme has the SerXAsn motif rather than the more unusual (confined to LMM class B enzymes) TyrXAsn combination of the more intensively studied R61 enzyme. We present here kinetic studies of $\mathbf{6}$ and 7, thia analogues of $\mathbf{4}$, reacting with the R39 enzyme, with emphasis on the transpeptidase and endopeptidase reactions. We also present $\mathrm{pH}$-rate profiles for the enzyme catalysis and the results of solvent kinetic isotope effect measurements. From these experiments, a clearer picture of the catalytic efficiency, specificity, and mechanism of action of the enzyme emerges.<smiles>CC(NC(=O)C(C)NC(=O)CCSC[C@H](N)[N+](=O)[O-])C(=O)O</smiles><smiles>CC(OC(=O)[O-])SC(=O)[C@H](C)NC(=O)CCSC[C@@H](N)C(=O)[O-]</smiles>

\section{MATERIALS AND METHODS}

The R39 DD-peptidase was expressed and purified as described previously (19). The following compounds were purchased commercially and used as received: $N$ - $\alpha$-Ac-Lys-D-Ala-D-Ala, $N$ - $\varepsilon$-Ac-D-Lys, $N$ - $\varepsilon$-Ac-L-Lys, and 4,4'-biphenyl-D-alanine (ChemImpex), $N$ - $\alpha$-Ac-L-Lys-D-Ala-D-Lys(Ac) (New England Peptide), D-alanine and L-alanine (Fluka), D-lactic acid (Bachem), (R)-2-amino-1-propanol (D-alaninol) (Acros), and D-Lys[Ac-Ala(D-iGln)] (NeoMPS). D- $\alpha$-Phenylglycine, D-homophenylalanine, D-tyrosine, D-leucine, D-phenylalanine, D-phenylactic acid, D-norleucine, and 2,6-diaminopimelic acid were all supplied by Sigma-Aldrich. Cefotaxime (16) and 7- $\beta$-aminocephalosporanic acid (17) were gifts from Merck and Eli Lilly and Co., respectively. 6- $\alpha$-D-Aminopimelyl- $\varepsilon$-D-alanyl-D-alanine (4) was available from previous studies in this laboratory (11). 3-(DCysteinyl)-propanoyl-D-alanyl-D-alanine (6) and 3-(D-cysteinyl)propanoyl-D-alanyl-D-thiolactate (7) were prepared using a general method described previously (21); details of these syntheses are provided in Supporting Information.

Kinetic Methods. All kinetic measurements were carried out in $20 \mathrm{mM}$ MOPS buffer at $\mathrm{pH} 7.5$ and $25^{\circ} \mathrm{C}$, unless otherwise noted. A mixed buffer was employed for the $\mathrm{pH}$ profiles and certain other experiments. This buffer contained $20 \mathrm{mM}$ each of acetate, MES, MOPS, TAPS, AMPSO, and CAPS, and ionic strength was maintained at $1.0 \mathrm{M}$ with sodium chloride. Absorption spectra and spectrophotometric reaction rates and progress curves were obtained by means of a Hewlett-Packard 8452A spectrophotometer. The enzyme-catalyzed reactions were monitored spectrophotometrically at $230 \mathrm{~nm}\left(\Delta \varepsilon=57 \mathrm{~cm}^{-1} \mathrm{M}^{-1}\right)$ (4), $230 \mathrm{~nm}\left(\Delta \varepsilon=100 \mathrm{~cm}^{-1} \mathrm{M}^{-1}\right)(6), 240 \mathrm{~nm}\left(\Delta \varepsilon=4980 \mathrm{~cm}^{-1}\right.$ $\left.\mathrm{M}^{-1}\right)(7), 230 \mathrm{~nm}\left(\Delta \varepsilon=76 \mathrm{~cm}^{-1} \mathrm{M}^{-1}\right)(\mathbf{1 1})$, and $230 \mathrm{~nm}(\Delta \varepsilon=$ $\left.92 \mathrm{~cm}^{-1} \mathrm{M}^{-1}\right)(\mathbf{1 5})$. Steady-state kinetic parameters for hydrolysis of the above substrates by the R39 DD-peptidase were obtained from measurements of initial rates as a function of substrate concentrations. These were fitted to the Michaelis-Menten-Henri equation by a nonlinear least-squares procedure (Kaleidograph).

The reactions of $\mathbf{4}$ and $\mathbf{6}$ were also monitored by ${ }^{1} \mathrm{H}$ NMR spectroscopy. Reaction mixtures, in $\mathrm{D}_{2} \mathrm{O}$, contained the substrate $(6.3 \mathrm{mM})$, enzyme $(30 \mathrm{nM})$, and buffer $(50 \mathrm{mM}$ sodium bicarbonate). Spectra were recorded immediately after addition of enzyme and at appropriate times thereafter.

The rates of formation and decay of intermediates in the reactions of $\mathbf{6}$ with the R39 DD-peptidase were quantitatively monitored by a HPLC method. Reaction mixtures of 6 ( $300 \mu \mathrm{L}$, $2.0 \mathrm{mM})$ and enzyme $(0.25 \mu \mathrm{M})$ in $20 \mathrm{mM}$ mixed buffer, $\mathrm{pH} 7.50$, were prepared and incubated at $25{ }^{\circ} \mathrm{C}$. At appropriate times, aliquots $(20 \mu \mathrm{L})$ were withdrawn and injected into a Varian Prostar 210 HPLC system equipped with a Varian $340 \mathrm{UV} /$ vis 
detector. Separation was achieved on a Macherey-Nagel Nucleosil 5 C-18 column with a mobile phase of $1 \%(\mathrm{v} / \mathrm{v})$ acetonitrile/water, also containing $0.05 \%$ TFA. A flow rate of 0.9 $\mathrm{mL} / \mathrm{min}$ was employed, and the effluent was monitored at $215 \mathrm{~nm}$. Under these conditions, retention times of the substrate $\mathbf{6}$, the hydrolysis product $\mathbf{8}$, and the two intermediates, $\mathrm{S}_{2}$ and $\mathrm{S}_{3}$, were $5.8,4.9,26.7$, and $36.7 \mathrm{~min}$, respectively. The fractions containing $S_{2}$ and $S_{3}$ were subjected to electrospray mass spectroscopy (Thermofinnigan LCQ Advantage). This experiment was repeated with 4 where retention times of the substrate and hydrolysis product were 7.1 and $5.9 \mathrm{~min}$, respectively.

Kinetics of turnover of $\mathbf{6}$ were studied in a similar experiment. In this case, $20 \mu \mathrm{L}$ aliquots of the reaction mixture were taken at appropriate times. In each aliquot, the reaction was quenched by its addition to $20 \mu \mathrm{L}$ of an aqueous solution containing $1 \%$ acetonitrile, $0.05 \%$ TFA, and $0.4 \mathrm{mM}$ D-phenylalanine. Each was then frozen immediately and later analyzed by HPLC as described above. The D-phenylalanine (retention time 13.5 min) was added as a concentration reference. The integrated HPLC peak areas as a function of time were taken as proportional to the concentrations of reactants, products, and intermediates as a function of time and fitted to appropriate reaction schemes by means of the KinTek version 2.0 (22) and Dynafit version 3.28 (23) programs. The former was particularly useful since it allowed the fixing of rate constant ratios. The two programs did, however, when comparably restrained, produce essentially the same fit with the data from the above experiments.

In order to obtain rate data directly for the intermediates $S_{2}$ and $S_{3}$, freeze-dried HPLC fractions of these species, isolated as described above, were dissolved in $350 \mu \mathrm{L}$ of the mixed buffer, and enzyme, to final concentrations of 5.0 and $61 \mathrm{nM}$, respectively, was added to $100 \mu \mathrm{L}$ portions. The subsequent reaction of each species was then monitored by HPLC, as described above, and the resulting progress curves were analyzed by means of the Dynafit program (23). In the case of $\mathrm{S}_{2}$, the absolute concentration of the peptide was obtained by analysis of D-alanine (24) in the final reaction mixture after complete reaction.

The $\mathrm{pH}$ profiles of $k_{\text {cat }} / K_{\mathrm{m}}$ for 7, 11, and 15 were obtained directly from spectrophotometric experiments run under [S] $\ll K_{\mathrm{m}}$ conditions as a function of $\mathrm{pH}$ in the mixed buffer. Reactions of the R39 DD-peptidase with the cephalosporins 16 and 17 were studied fluorometrically $\left(\lambda_{\mathrm{ex}}=280 \mathrm{~nm}, \lambda_{\mathrm{f}}=\right.$ $340 \mathrm{~nm})(25)$. The reaction mixture, in mixed buffer, contained $16(5.0 \mu \mathrm{M})$ or $17(30 \mu \mathrm{M})$ and enzyme $(0.57 \mu \mathrm{M})$. For both the peptides and cephalosporins, time traces were fitted to an exponential function to obtain pseudofirst-order rate constants that were converted to secondorder constants $\left(k_{\text {cat }} / K_{\mathrm{m}}\right.$ or $\left.k_{2} / K_{1}\right)$ by dividing them by the relevant peptide/cephalosporin concentration. The $\mathrm{pH}$ dependences of these parameters were fitted to eq 1 for a double dissociation model to obtain $\mathrm{p} K_{\mathrm{a}}$ values. In this equation, $k_{2}$ represents $k_{\text {cat }} / K_{\mathrm{m}}$ when all enzyme is present in the monoprotonated form.

$$
k_{\text {cat }} / K_{\mathrm{m}}=k_{2} K_{\mathrm{a} 1} h /\left(h^{2}+K_{\mathrm{a} 1} h+K_{\mathrm{a} 1} K_{\mathrm{a} 2}\right)
$$

The $\mathrm{pH}$ dependence of $k_{\text {cat }}$ for 7 was fitted to eq 2 , where $k_{1}$ represents a low $\mathrm{pH}$ plateau.
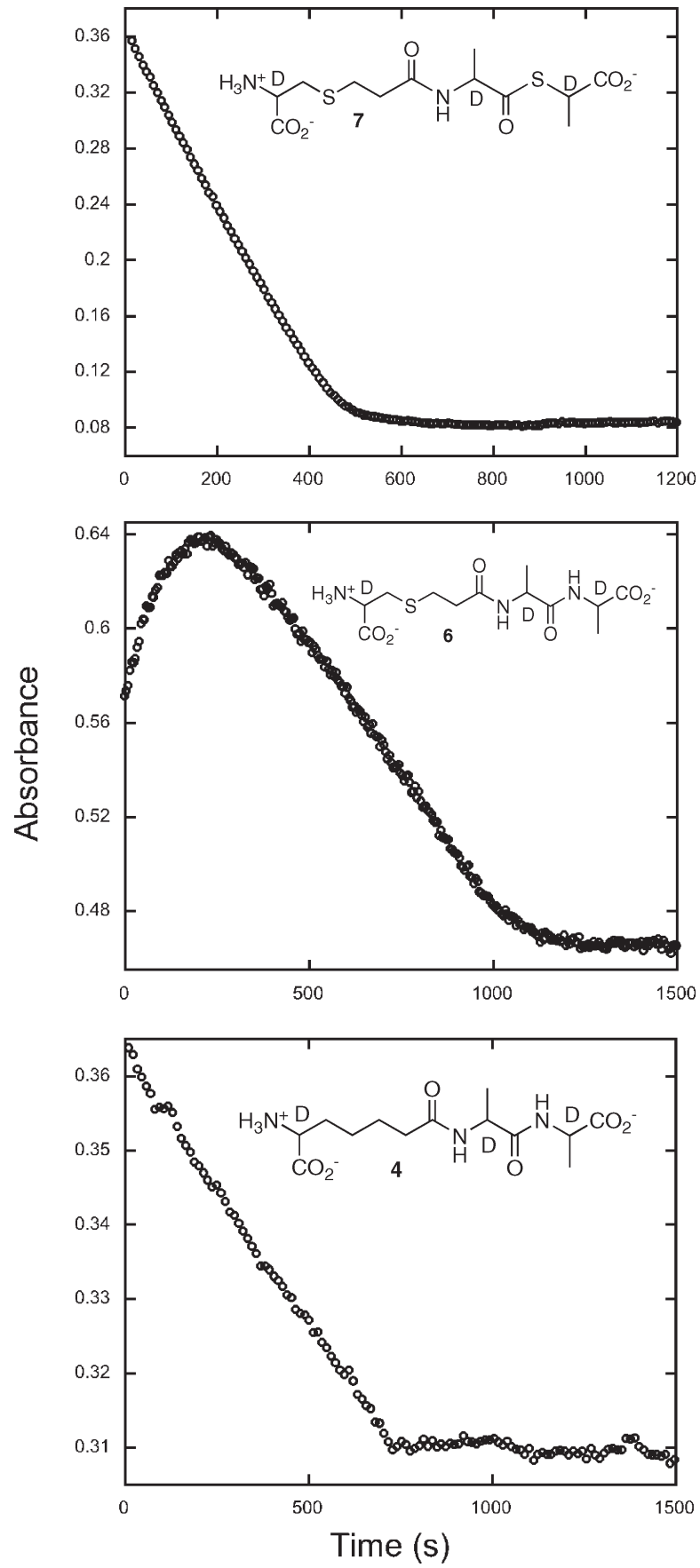

FIGURE 1: Total progress curves for reaction of 7 (100 $\mu \mathrm{M})$ (top), 6 (2.0 $\mathrm{mM})$ (middle), and $4(1.0 \mathrm{mM})$ (bottom) with the R39 DDpeptidase $(0.24 \mu \mathrm{M})$. Data are shown at 240, 230, and $230 \mathrm{~nm}$, respectively.

$$
\log k_{\text {cat }}=\log \left[\left(k_{1} h+k_{2} K_{\mathrm{a}}\right) /\left(h+K_{\mathrm{a}}\right)\right]
$$

Solvent Kinetic Isotope Effects. The solvent deuterium kinetic isotope effects ${ }^{\mathrm{D}} V / K$ and ${ }^{\mathrm{D}} V$ for hydrolysis of 7 and $\mathbf{1 5}$ by the R39 DD-peptidase were determined from spectrophotometric rates in $20 \mathrm{mM}$ MOPS buffer, $\mathrm{pH} / \mathrm{pD} 7.5$, as previously described (26). Substrate concentrations of ca. $0.1 K_{\mathrm{m}}$ and $5 K_{\mathrm{m}}$ were used for ${ }^{\mathrm{D}} V / K$ and ${ }^{\mathrm{D}} V$ determinations, respectively. Appropriate corrections for the degree of saturation were made in each case (27). A common concentrated enzyme stock solution in 1/1 (v/v) $\mathrm{H}_{2} \mathrm{O} / \mathrm{D}_{2} \mathrm{O}$ MOPS buffer, $\mathrm{pH}$ meter reading 7.3, was used. Substrate solutions were separately prepared in $\mathrm{H}_{2} \mathrm{O}$ or $\mathrm{D}_{2} \mathrm{O}$. 


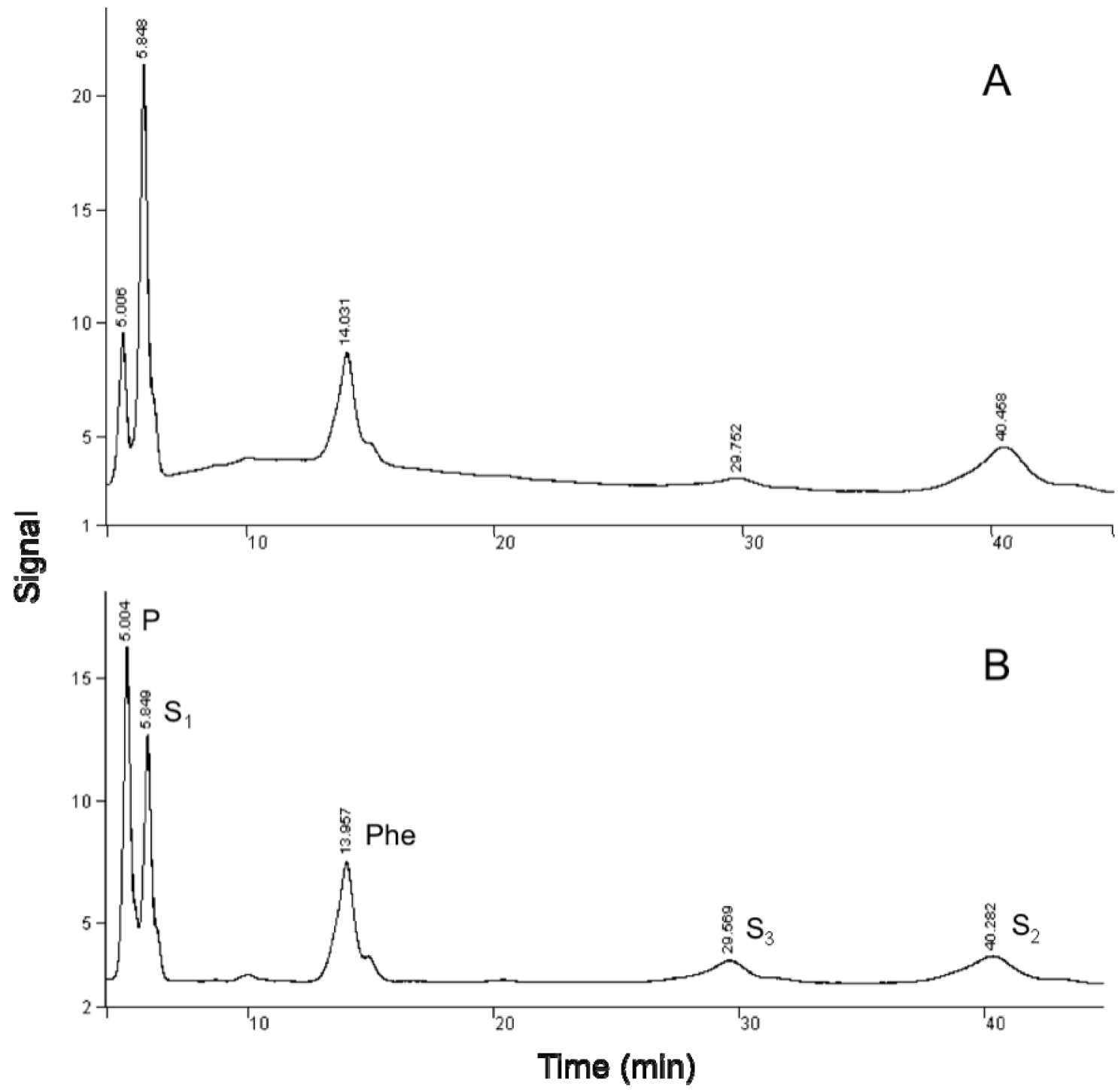

FiguRE 2: HPLC traces of samples taken at $3 \mathrm{~min}(\mathrm{~A})$ and $7 \mathrm{~min}(\mathrm{~B})$ from the reaction mixture of $6(2 \mathrm{mM})$ and the R39 DD-peptidase $(0.25 \mu \mathrm{M})$. The signals are proportional to the absorbance at $215 \mathrm{~nm}$. D-Phenylalanine $(0.4 \mathrm{mM})$ was added as a concentration reference. Retention times are noted above the peaks.

Aminolysis Kinetics. Spectrophotometric initial rate measurements were also used to obtain kinetic parameters for aminolysis of $7(50 \mu \mathrm{M})$ by the R39 DD-peptidase $(40 \mathrm{nM})$ in MOPS buffer at $\mathrm{pH} 7.5$ (29). These data were then analyzed in terms of Scheme 7.

\section{RESULTS AND DISCUSSION}

Peptide $\mathbf{4}$ is an excellent substrate of the R39 DD-peptidase, most likely because of its resemblance to a specific element of the stem peptide $\mathbf{5}$, as described in the introduction. The analogues $\mathbf{6}$ and 7 were prepared to facilitate synthesis and kinetics studies. Thia derivatives of $\mathbf{2}$ have previously been used in studies of the R61 DD-peptidase $(21,31)$. The reactions of D-thiolactates are more readily monitored spectrophotometrically than those of peptides, and the leaving group ability of the thiolate often ensures that deacylation is ratedetermining (29-31).

Spectrophotometric initial rates of turnover of 7 , like those of $4(11)$, were readily obtained (Figure 1A). Interesting complications arose immediately, however, on investigation of $\mathbf{6}$. Figure 1B shows a typical spectrophotometric trace of the reaction between $\mathbf{6}$ and the R39 DD-peptidase. Figure 1C shows a comparable trace for $\mathbf{4}$. The reaction of $\mathbf{6}$ appears to contain two separate phases, the faster involving an increase in absorbance at $230 \mathrm{~nm}$ and the slower the anticipated (Figure 1C) decrease accompanying peptide hydrolysis. Experiment showed that both phases were enzyme-catalyzed, and thus the first phase was not an artifact.

In order to understand the complex kinetics of reaction of $\mathbf{6}$, the composition of a reaction mixture (initial concentrations of enzyme and 6 were $0.25 \mu \mathrm{M}$ and $2.0 \mathrm{mM}$, respectively) was monitored as a function of time by HPLC, as described in the Materials and Methods section. Panels A and B of Figure 2 show absorbance chromatograms at 3.0 and $7.0 \mathrm{~min}$, respectively. The chromatograms show $\mathbf{6}$ (marked as $\mathrm{S}_{1}$ ) and the expected hydrolysis product $\mathbf{8}$ (marked as $\mathrm{P}$ ) but also what are apparently intermediate species $S_{2}$ and $S_{3}$ that form and decay as a function of time. Figure $3 \mathrm{~A}$ shows the time dependence of concentrations of $6, \mathrm{~S}_{2}, \mathrm{~S}_{3}$, and $\mathbf{8} .{ }^{1} \mathrm{H}$ NMR spectra of a reaction mixture (not shown) also indicated the presence of at least one accumulating intermediate. Upon completion of all reactions, the NMR spectrum was consistent with that of a mixture of $\mathbf{8}$ and 


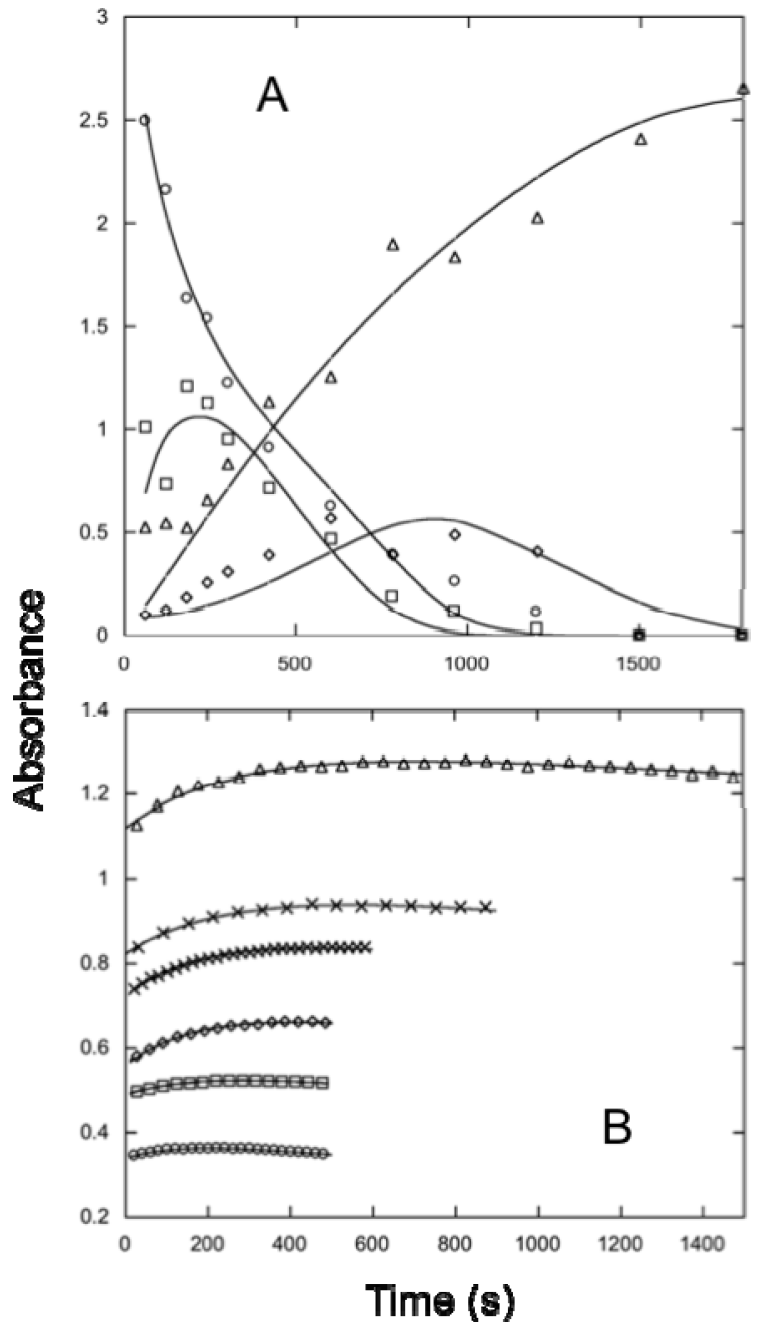

FIGURE 3: (A) Variation of concentration (the signal is proportional to the absorbance at $215 \mathrm{~nm})$ of $\mathrm{S}_{1}(\bigcirc), \mathrm{S}_{2}(\square), \mathrm{S}_{3}(\diamond)$, and $\mathrm{P}(\triangle)$ as a function of time on reaction of $6(2 \mathrm{mM})$ in the presence of the R39 DD-peptidase $(0.25 \mu \mathrm{M})$. (B) The same reaction followed directly spectrophotometrically at $230 \mathrm{~nm}$. Concentrations of 6 were $1.0 \mathrm{mM}$ $(\bigcirc), 1.5 \mathrm{mM}(\square), 2.0 \mathrm{mM}(\diamond), 2.5 \mathrm{mM}(\nabla), 3.0 \mathrm{mM}(\times)$, and $4.0 \mathrm{mM}$ $(\triangle)$, and the enzyme concentration was $0.13 \mu \mathrm{M}$. The points are experimental, and the lines represent a simultaneous fit of all data to Scheme 6 (see text)

Scheme 2

$$
\begin{aligned}
\mathrm{S}_{1} \stackrel{\mathrm{C}}{\longrightarrow} \mathrm{P}+\text { D-Ala } \\
\mathrm{S}_{1}+\mathrm{S}_{1} \stackrel{\mathrm{T}}{\longrightarrow} \mathrm{S}_{2}+\text { D-Ala } \\
\mathrm{S}_{2} \stackrel{\mathrm{C}}{\longrightarrow} \mathrm{S}_{3}+\text { D-Ala } \\
\mathrm{S}_{3} \stackrel{\mathrm{E}}{\longrightarrow} 2 \mathrm{P}
\end{aligned}
$$

D-alanine. At short reaction times, the $\mathrm{S}_{2}$ species was observed to arise first, followed by $S_{3}$; the simplest interpretation, therefore, would suggest that $\mathrm{S}_{3}$ is a product of reaction of $\mathrm{S}_{2}$. The hydrolysis product of $\mathbf{6}$ (viz., 8), however, appears to increase in concentration directly from time zero and thus cannot solely be a product of $S_{3}$. In the NMR experiment, D-alanine was also observed to increase directly from time zero. Figure 3B shows the results of spectrophotometric experiments designed to get

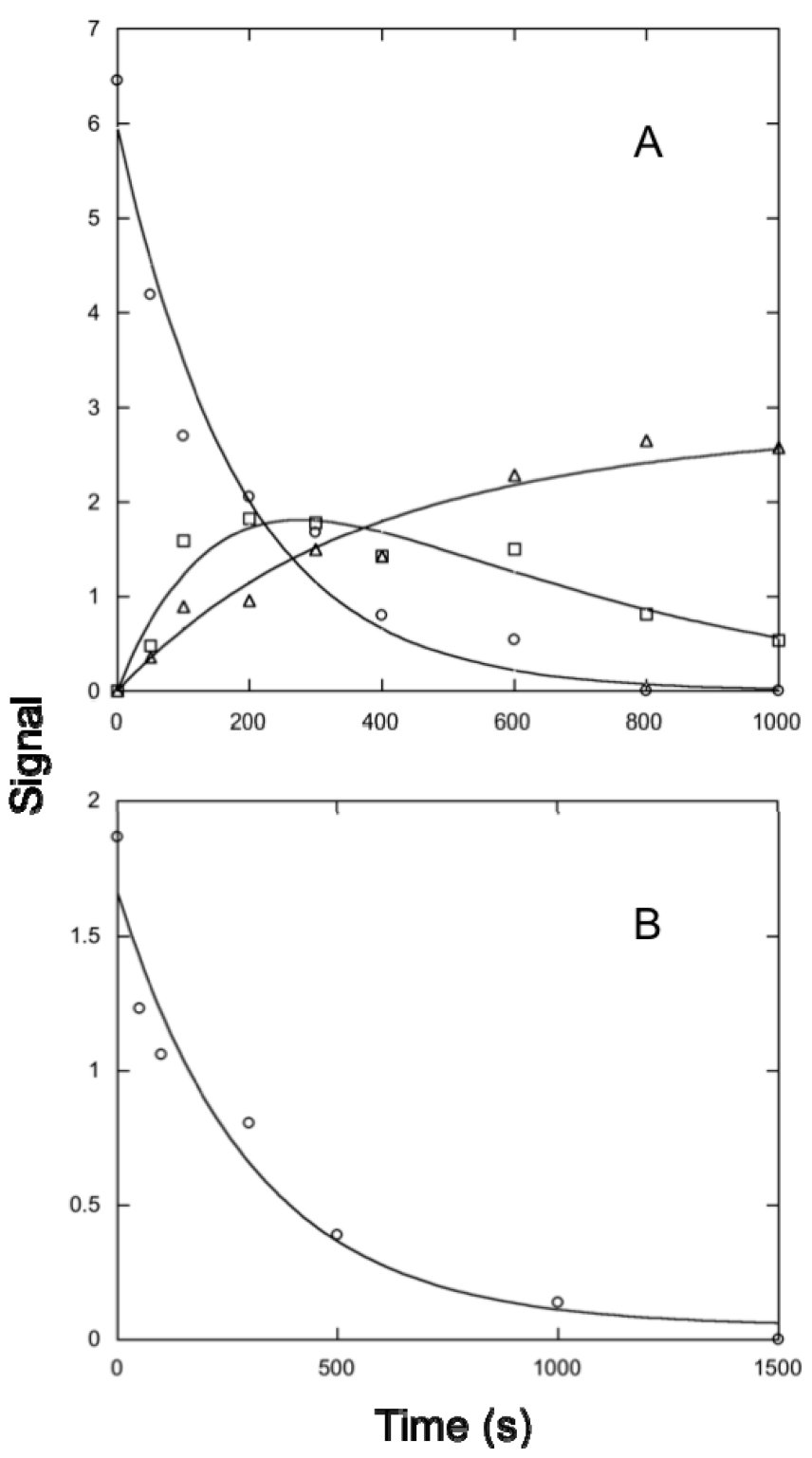

Figure 4: (A) Variation of the concentration (the signal is proportional to the absorbance at $215 \mathrm{~nm}$ ) of $S_{2}(O), S_{1}(\square)$, and $P(\triangle)$ as a function of time on reaction of $S_{2}(0.37 \mathrm{mM})$ in the presence of the R39 DD-peptidase $(5.0 \mathrm{nM})$. (B) Disappearance of $\mathrm{S}_{3}$ in the presence of the R39 DD-peptidase $(61 \mathrm{nM})$. The points are experimental, and the lines represent a fit of the data to Schemes 4 and 5, respectively (see text).

more quantitative data for the first phase of reaction (see above).

$$
\text { (n) }
$$

In a preparative experiment, samples of $\mathrm{S}_{2}$ and $\mathrm{S}_{3}$, formed on reaction of $\mathbf{6}$ as described above, were isolated by HPLC and subjected to $\mathrm{ES}(+)$ mass spectral analysis. The molecular masses 
Scheme 3

$$
\begin{aligned}
\mathrm{S}_{1} \stackrel{\mathrm{C}}{\longrightarrow} \mathrm{P}+\text { D-Ala } \\
\mathrm{S}_{1}+\mathrm{S}_{1} \stackrel{\mathrm{T}}{\rightleftharpoons} \mathrm{S}_{2}+\text { D-Ala } \\
\mathrm{S}_{1}+\mathrm{P} \stackrel{\mathrm{T}}{\rightleftharpoons} \mathrm{S}_{3}+\text { D-Ala }
\end{aligned}
$$

Scheme 4

$$
\begin{aligned}
& \mathrm{E}+\mathrm{S}_{2} \stackrel{\mathrm{E}}{\longrightarrow} \mathrm{E}+\mathrm{S}_{1}+\mathrm{P} \\
& \mathrm{E}+\mathrm{S}_{1} \stackrel{\mathrm{C}}{\longrightarrow} \mathrm{E}+\mathrm{P}+\text { D-Ala }
\end{aligned}
$$

Scheme 5

$$
\mathrm{E}+\mathrm{S}_{3} \stackrel{\mathrm{E}}{\longrightarrow} \mathrm{E}+2 \mathrm{P}
$$

Scheme 6

$$
\begin{aligned}
& E+S_{1} \frac{k_{1}}{k_{-1}} \text { E.S } 1 \\
& \text { E.S } \frac{\mathrm{k}_{2}}{\mathrm{k}_{-2}} \mathrm{ES}_{1}+\mathrm{A} \\
& \mathrm{ES}_{1} \stackrel{\mathrm{k}_{3}}{\longrightarrow} \mathrm{E}+\mathrm{P} \\
& \mathrm{ES}_{1}+\mathrm{S}_{1} \stackrel{\mathrm{k}_{4}}{\underset{\mathrm{k}_{-4}}{\mathrm{k}_{5}}} \mathrm{E} \mathrm{S}_{2} \\
& \text { E.S } 2 \stackrel{k_{5}}{k_{-5}} E+S_{2} \\
& E S_{1}+P \quad \frac{k_{6}}{k_{-6}} \quad E . S_{3} \\
& \text { E.S } \frac{\mathrm{k}_{7}}{\mathrm{k}_{-7}} \mathrm{E}+\mathrm{S}_{3}
\end{aligned}
$$

Table 1: Steady-State Kinetic Parameters for Reaction of the R39 DDPeptidase with Peptide $\mathbf{6}^{a}$

\begin{tabular}{lll}
\hline \multicolumn{1}{c}{ parameter } & \multicolumn{1}{c}{ value } & \multicolumn{1}{c}{ provenance } \\
\hline$k_{1}\left(\mathrm{~s}^{-1} \mathrm{M}^{-1}\right)$ & $2.0 \times 10^{8}$ & assumed, fixed \\
$k_{2} / k_{-1}$ & $1.5 \times 10^{-3}$ & experiment, ${ }^{b}$ fixed \\
$k_{-2}\left(\mathrm{~s}^{-1} \mathrm{M}^{-1}\right)$ & 500 & experiment, fixed \\
$k_{3}\left(\mathrm{~s}^{-1}\right)$ & 9.5 & experiment, fixed \\
$k_{4}\left(\mathrm{~s}^{-1} \mathrm{M}^{-1}\right)$ & $(1.4 \pm 0.1) \times 10^{4}$ & fitted \\
$k_{-4} / k_{5}$ & $5.0 \times 10^{-3}$ & experiment, ${ }^{b}$ fixed \\
$k_{-5}$ & $2.0 \times 10^{8}$ & assumed, fixed \\
$k_{6}\left(\mathrm{~s}^{-1} \mathrm{M}^{-1}\right)$ & $(3.0 \pm 0.1) \times 10^{3}$ & fitted \\
$k_{-6} / k_{7}$ & $2.5 \times 10^{-4}$ & experiment, ${ }^{b}$ fixed \\
$k_{-7}\left(\mathrm{~s}^{-1} \mathrm{M}^{-1}\right)$ & $2.0 \times 10^{8}$ & assumed, fixed \\
\hline
\end{tabular}

${ }^{a}$ Determined from experiments in mixed buffer. ${ }^{b}$ Calculated from $k_{\text {cat }} / K_{\mathrm{m}}$ values for $\mathrm{S}_{1}(\mathbf{6}), \mathrm{S}_{2}(\mathbf{9})$, and $\mathrm{S}_{3}(\mathbf{1 0})$.

determined, 582.2 and 511.2 respectively, indicated that $S_{2}$ and $S_{3}$ are 9 and 10, respectively. Thus, Scheme 2 seemed reasonable, with $\mathbf{9}$ and $\mathbf{1 0}$ arising from transpeptidation reactions of $\mathbf{6}$ with itself and with $\mathbf{8}$, respectively. In separate experiments, enzyme was added to solutions of isolated $\mathrm{S}_{2}$ and $\mathrm{S}_{3}$, and the subsequent reaction in each case was followed by HPLC. The results (Figure
Table 2: Steady-State Rate Parameters for Hydrolysis of Substrates by the R39 DD-Peptidase ${ }^{a}$

\begin{tabular}{llll}
\hline substrate & \multicolumn{1}{c}{$k_{\text {cat }}\left(\mathrm{s}^{-1}\right)$} & $K_{\mathrm{m}}(\mu \mathrm{M})$ & $k_{\text {cat }} / K_{\mathrm{m}}\left(\mathrm{s}^{-1} \mathrm{M}^{-1}\right)$ \\
\hline $\mathbf{4}$ & 5.2 & 4.9 & $1.1 \times 10^{6}$ \\
$\mathbf{6}$ & $4.3 \pm 0.2(9.5 \pm 0.5)^{b}$ & $59 \pm 5$ & $7.3 \times 10^{4}$ \\
& & & $3.0 \times 10^{5 b, c}$ \\
$\mathbf{7}$ & $3.0 \pm 0.1$ & $3.8 \pm 0.4$ & $8.0 \times 10^{5}$ \\
$\mathbf{9}^{b, c}$ & 9.5 & 9.5 & $1.05 \times 10^{6}$ \\
$\mathbf{1 0} \mathbf{0}^{b, c}$ & 9.5 & 190 & $4.9 \times 10^{4}$ \\
$\mathbf{1 1}$ & $11.8 \pm 0.4$ & $260 \pm 40$ & $4.5 \times 10^{4}$ \\
$\mathbf{1 5}$ & $26.5 \pm 0.8$ & $140 \pm 30$ & $1.9 \times 10^{5}$ \\
\hline
\end{tabular}

${ }^{a}$ All represent hydrolysis of terminal D-alanine or D-thiolactate except for 9 and 10 (see text). ${ }^{b}$ Determined in mixed buffer. ${ }^{c}$ Calculated from Table 1 .

4) indicate that $S_{3}$ proceeds directly to the final hydrolysis product $\mathrm{P}(\mathbf{8})$, as would be expected; no $\mathrm{S}_{2}$ was observed. On the other hand, reaction of $S_{2}$ appeared to produce, first, $S_{1}$ and then $\mathrm{P} ;$ no $\mathrm{S}_{3}$ was observed on reaction of $\mathrm{S}_{2}$, despite expectations based on the simplest interpretation of Figure 3A. This phenomenon cannot arise because $S_{3}$ reacts faster than $S_{2}$ and thus is unobserved in Figure 4B, because this is contrary to the observations of Figure 3A. The conclusion must be that $S_{3}$ is not a product of reaction of $S_{2}$, at least not at a rate observable under the conditions of these experiments. These observations therefore cannot be accommodated by Scheme 2 but can be, most simply, by Scheme 3.

Scheme 3 shows that the R39 DD-peptidase is able to catalyze the carboxypeptidation $(\mathrm{C})$ reaction of $\mathrm{S}_{1}$ and the transpeptidation reaction (T) of $\mathrm{S}_{1}$ with either itself or $\mathrm{P}$ as nucleophile. The other notable feature is that the enzyme prefers to act as a transpeptidase or endopeptidase (E) in its reaction with $S_{2}$ rather than as a carboxypeptidase; this may be relevant to its role in vivo (see below).

To proceed further, the data of Figure 4 were quantitatively fitted to Schemes 4 and 5, respectively, where the endopeptidase (E) reactions of both $\mathrm{S}_{2}$ and $\mathrm{S}_{3}$ are noted.

With values of $k_{\text {cat }} / K_{\mathrm{m}}$ for $\mathrm{S}_{2}$ and $\mathrm{S}_{3}$ in hand from these fits, the full Scheme 6 was then applied to the data of Figure 3 with the restraints listed in Table 1. In this scheme, E.S, E. $S_{2}$, and $E . S_{3}$ represent noncovalent complexes of the enzyme with $S_{1}, S_{2}$, and $S_{3}$, respectively, and $\mathrm{ES}_{1}$ is the $\alpha$-D-aminopimelyl acyl-enzyme.

This procedure yielded the fitted lines shown in Figure 3 and the rate constant data of Table 1. It might be noted in passing here that omission of specific E.S $S_{2}$ and E.S $S_{3}$ complexes from Scheme 6 led to a noticeably poorer fit.

The first important results coming from the above quantitative treatment are the calculated $k_{\mathrm{cat}} / K_{\mathrm{m}}$ values for $\mathbf{6}\left[k_{1} k_{2} /\left(k_{-1}+k_{2}\right)\right]$, $\mathbf{9}\left[k_{-4} k_{-5} /\left(k_{-4}+k_{5}\right)\right]$ and $\mathbf{1 0}\left[k_{-6} k_{-7} /\left(k_{-6}+k_{7}\right)\right]$ in the reactions shown in Scheme 6, viz., $3.0 \times 10^{5} \mathrm{~s}^{-1} \mathrm{M}^{-1}, 1.0 \times 10^{6} \mathrm{~s}^{-1} \mathrm{M}^{-1}$, and $5.0 \times 10^{4} \mathrm{~s}^{-1} \mathrm{M}^{-1}$, respectively. This shows, as noted above from qualitative assessment of the results, that the R39 DDpeptidase is an effective endopeptidase as well as a carboxypeptidase. In particular, the extended peptide 9 is a much better substrate (in the endopeptidase reaction) than $\mathbf{6}$ (in the carboxypeptidase reaction) or, as noted above, 9 itself (in the carboxypeptidase reaction). Similarly, $k_{4}>k_{6}>k_{-2}$, showing the greater effectiveness of extended nucleophiles $\left(\mathrm{S}_{1}>\mathrm{P}>\right.$ D-Ala) in the transpeptidase reaction of $\mathrm{ES}_{1}$.

As noted above, the kinetic complexity that led to the discovery of Scheme 6 was not observed, superficially at least, 
Scheme 7

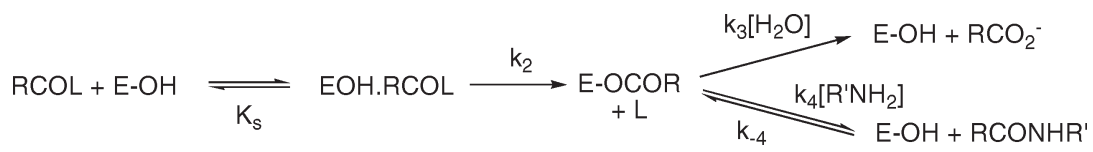

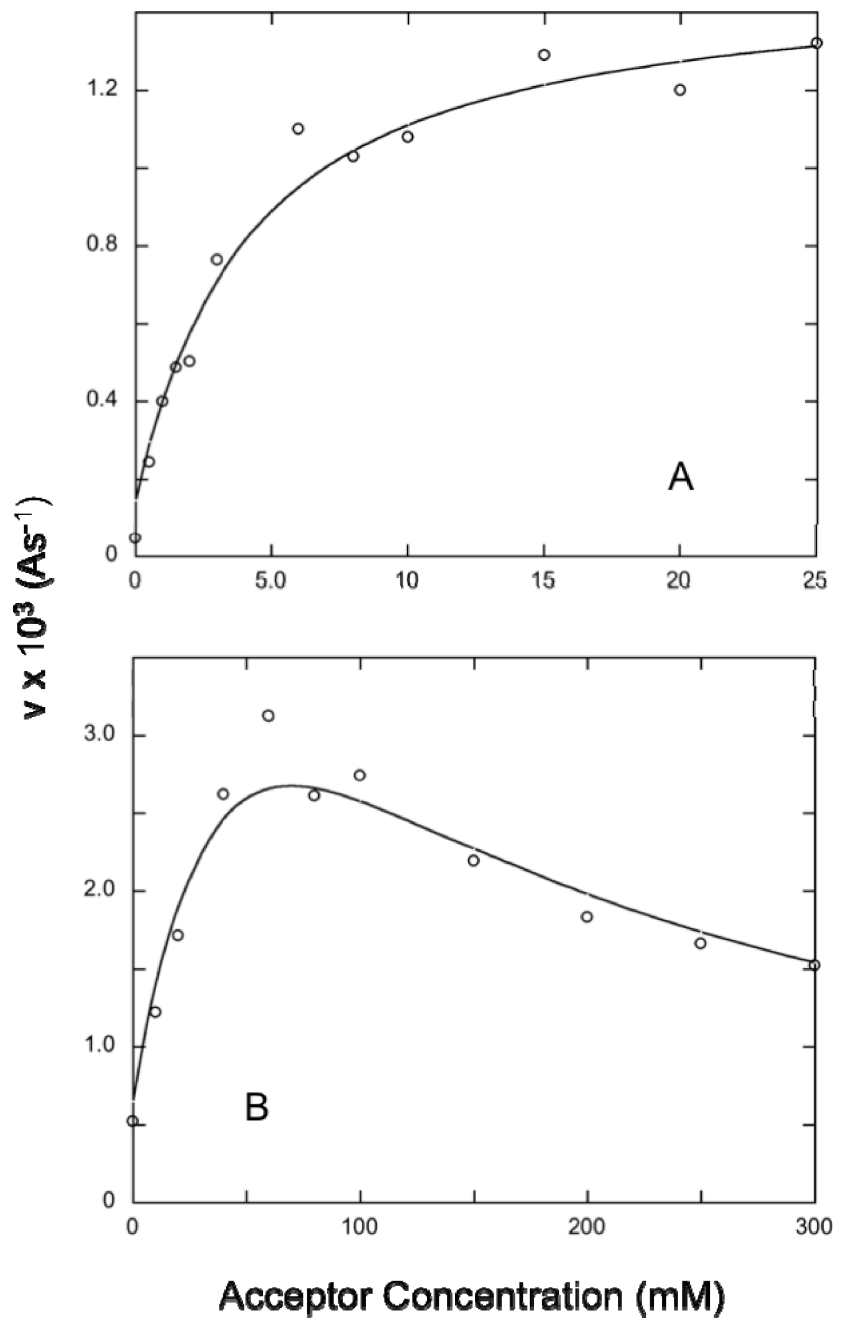

FIGURE 5: Effect of D-phenylalanine (A) and D-alanine (B) on turnover of $7(50 \mu \mathrm{M})$, catalyzed by the R39 DD-peptidase (13.3 and $40 \mathrm{nM}$, respectively). The points are experimental, and the lines represent the fit of the data to Schemes 7 and 8 (see text).

in the reactions of 4 and 7 under the same solution conditions. In the latter case, this is most likely because the reactions of 7 were studied at lower concentrations $(\leq 100 \mu \mathrm{M})$ because of the low $K_{\mathrm{m}}$ value of this substrate (Table 2). The case of $\mathbf{4}$ is more intriguing. HPLC and ${ }^{1} \mathrm{H}$ NMR experiments, which directly showed the presence of at least one intermediate during the hydrolysis of $\mathbf{6}$, revealed a clean hydrolysis of $\mathbf{4}$ under the same conditions. Either $\mathbf{4}$ is a much poorer acyl acceptor than $\mathbf{6}$, which seems unlikely, or the analogues of $\mathbf{9}$ and $\mathbf{1 0}$ derived from $\mathbf{4}$ are considerably better substrates of the enzyme than 4 itself and thus do not accumulate in solution as $\mathbf{4}$ reacts. The latter explanation is supported by the observation of more complex kinetics of reaction of $\mathbf{4}$ at $\mathrm{pH} 9.0$, analogous to those of $\mathbf{6}$ illustrated in Figure 1B. This also has interesting implications for the nature of the in vivo substrate of the R39 DD-peptidase (see below).
Table 3: Kinetic Parameters (Scheme 7) for Aminolysis of 7 by the R39 DDPeptidase

\begin{tabular}{llll}
\hline entry & \multicolumn{1}{c}{ acyl acceptor } & \multicolumn{1}{c}{$k_{4}\left(\mathrm{~s}^{-1} \mathrm{M}^{-1}\right)$} & \multicolumn{1}{c}{$K_{\mathrm{i}}(\mathrm{mM})$} \\
\hline 1 & D-alanine & $(5 \pm 3) \times 10^{2}$ & 70 \\
2 & L-alanine & no $(300)^{a}$ & no $(300)^{b}$ \\
3 & D-alaninol & $9.9 \pm 0.4$ & no $(200)^{b}$ \\
4 & D-lactate & $23 \pm 3$ & 100 \\
5 & D-phenylalanine & $(7.7 \pm 1.6) \times 10^{3}$ & no $(25)^{b}$ \\
6 & D-tyrosine & $(2.0 \pm 0.3) \times 10^{3}$ & no $(4.7)^{b}$ \\
7 & D- $\alpha$-phenylglycine & $(5.4 \pm 3.6) \times 10^{3}$ & 9.5 \\
8 & D-homophenylalanine & $(1.7 \pm 0.3) \times 10^{3}$ & no $(9.4)^{b}$ \\
9 & 4-biphenyl-D-alanine & $(9.3 \pm 1.7) \times 10^{3}$ & no $(0.4)^{b}$ \\
10 & D-norleucine & $(1.5 \pm 1.0) \times 10^{3}$ & 43 \\
11 & $N$ - $\varepsilon$-acetyl-D-lysine & $(7.1 \pm 2.5) \times 10^{3}$ & no $(94)^{b}$ \\
12 & $N$ - -acetyl-L-lysine & no $(300)^{a}$ & no $(300)^{b}$ \\
13 & 2,6-meso-diaminopimelic acid & $(1.0 \pm 0.2) \times 10^{3}$ & 4.5 \\
14 & D-Lys(Ac-L-Ala-D-iGln) & $(1.8 \pm 0.5) \times 10^{3}$ & 2.3 \\
$15^{c}$ & $\mathrm{~S}_{1}(\mathbf{6})$ & $(1.4 \pm 0.1) \times 10^{4 c}$ & no $(2.0)^{b}$ \\
16 & $\mathrm{P}_{1}(\mathbf{8})$ & $(3.0 \pm 0.1) \times 10^{3 c}$ & 0.48 \\
\hline
\end{tabular}

${ }^{a}$ no, no rate acceleration observed at the concentrations ( $\mathrm{mM}$ ) employed (in parentheses). ${ }^{b}$ no, no inhibition observed at the highest concentration employed (in parentheses). ${ }^{c}$ From Table 1.

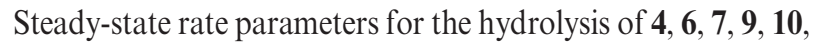
and 11, a generic, nonspecific peptide substrate for comparison, are presented in Table 2.<smiles>CC(NC(=O)C(C)NC(=O)C(C)NC(=O)C(=O)O)C(=O)O</smiles>

It is noticeable, first, that $\mathbf{6}$ is some 15 times poorer as a substrate $\left(k_{\mathrm{cat}} / K_{\mathrm{m}}\right)$ than 4 . This difference is very similar in magnitude to the effect of the analogous structural change in substrates of the R61 DD-peptidase and is probably due to the effect of thia substitution on the hydrophobic effect (21). The specificity of $\mathbf{4}$ as a substrate is best seen in comparison with 11, where the effect of the pimelyl carboxylate is evident. The thiolactate $\mathbf{7}$ is some 10 times more reactive than 6, reflecting the better leaving group, which would be expressed in the acylation rate and thus in $k_{\text {cat }} / K_{\mathrm{m}}\left(=k_{2} / K_{\mathrm{s}}\right.$, Scheme 7). A similar effect is observed in the analogous R61 DDpeptidase substrates (29).

Initial rates of hydrolysis of 7 increased markedly on addition of D-amino acids. Figure 5A, for example, shows the effect of D-phenylalanine. This result is typical of rate-determining deacylation $\left(k_{2}>k_{3}\left[\mathrm{H}_{2} \mathrm{O}\right]\right.$, Scheme 7$)$, where the acyl-enzyme can be attacked by both water and an amine nucleophile and where addition of the latter would be expected to increase the observed steady-state rate $(28,29)$. The increase in rate slows at high nucleophile concentration (Figure $5 \mathrm{~A}$ ) as $k_{4}\left[\mathrm{R}^{\prime} \mathrm{NH}_{2}\right]+k_{3}\left[\mathrm{H}_{2} \mathrm{O}\right]$ approaches $k_{2}$ and acylation takes over as the rate-determining step. The fit of the data of Figure $5 \mathrm{~A}$ to Scheme 7 led to a $k_{4}$ value of $(7.7 \pm 1.6) \times 10^{3} \mathrm{~s}^{-1} \mathrm{M}^{-1}$ for D-phenylalanine. Thus, it seems likely that during hydrolysis of 7 under conditions of saturation of the R39 DD-peptidase, deacylation $\left(k_{3}\right)$ is rate-determining. The close similarity between the $k_{\text {cat }}$ values of $\mathbf{6}$ and $\mathbf{7}$ suggests that this is true for the peptide $\mathbf{6}$ as well. 
Scheme 8

$$
\mathrm{E}-\mathrm{OH}+\mathrm{R}^{\prime} \mathrm{NH}_{2} \underset{\mathrm{K}_{\mathrm{i}}}{\rightleftharpoons} \mathrm{EOH} \cdot \mathrm{R}^{\prime} \mathrm{NH}_{2}
$$

The specificity of the amino acid acceptor $\mathrm{R}^{\prime} \mathrm{NH}_{2}$ is of interest since, assuming the simple Scheme 7, it should also be an indicator of leaving group specificity in the peptide substrate RCONHR $^{\prime}$ of the endopeptidase reaction. The experiment described above for D-phenylalanine was repeated with a number of potential amino acceptors with the results shown in Table 3. Note that the issue of whether the bound species here is the amino acid anion or the zwitterion is moot; the zwitterion would certainly be the dominant species in solution at $\mathrm{pH} 7.5$, but the reactive and thus, perhaps, bound form may be the anion. It should also be noted that with several acyl acceptors an initial increase in rate at low concentration, as in Figure 5A, was followed by a rate decrease at higher concentrations, as seen with D-alanine in Figure 5B, for example. This phenomenon was interpreted as reflecting competitive inhibition by the D-amino acid (Scheme 8) and incorporated into Scheme 7 for data fitting. It is certainly not unreasonable to find that a D-amino acid could compete with the D-aminopimelyl terminus of $\mathbf{6}$ for the acyl donor site. Similar inhibition was observed in studies of the R61 DD-peptidase $(10,29)$.

The first four entries of Table 3 affirm the importance of D-stereochemistry of the amino acid in an effective acceptor. The next six demonstrate that incorporation of hydrophobic moieties adjacent to the polar terminus is beneficial. Entries 11-13 represent analogues of what would be a natural acyl acceptor in a transpeptidation reaction in vivo (Scheme 1). Compounds $\mathbf{1 2}$ and $\mathbf{1 3}$ are probably the closest analogues to a natural acceptor, and it is seen that $N$ - $\varepsilon$-acetyl-D-lysine $\mathbf{1 2}$ is significantly more effective than the acceptor of entry 14 (13).

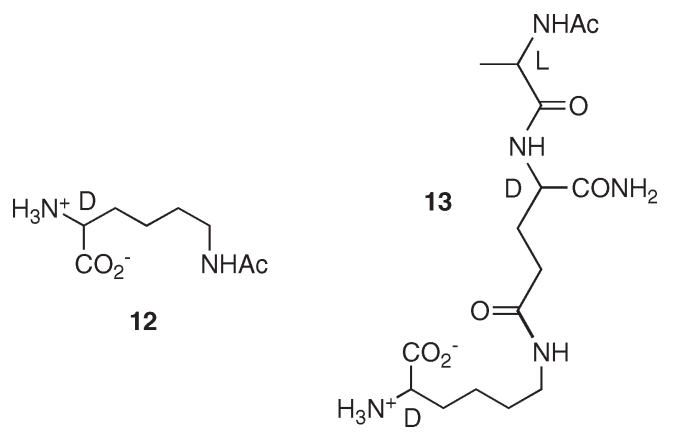

As in the acyl donor (11), there seems little particular affinity for the L-Ala-D-iGln moiety in an acyl acceptor (13). The kinetics of turnover of $\mathbf{6}$, discussed above, show that $\mathbf{6}$ is a better acceptor than the others of Table 3, including 8 . The final hydrolysis product 8 was, at high concentration, also an inhibitor, with a $K_{\mathrm{i}}$ value of $(0.48 \pm 0.05) \mathrm{mM}$. This is the strongest inhibition observed, but $\mathbf{8}$ has the side chain $\mathrm{N}$-terminus closest in structure to that of the good substrates 4 and 6.

It is interesting to compare the results above with those of comparable experiments with the R61 DD-peptidase $(28,29,32)$. First, the transpeptidation reaction of the R61 enzyme is asymmetric in that, although the leaving group would be D-alanine, as usual, the incoming nucleophile would be an N-terminal glycylpeptide (see 1). This suggests that there must be two rather different acyl acceptor binding sites adjacent to the acyl donor site in this enzyme. Some evidence for this idea has been obtained (29). Certainly, both D-amino acids and GlyL-X dipeptides can play the role of acyl acceptor (29). This may also be the case with respect to the R39 DD-peptidase where there is also asymmetry, but here both leaving group (D-alanine) and nucleophile (D-aminopimelyl) are D-amino acid derivatives and thus, in principle, only one binding site for the acceptor may be needed. Some further investigation of this issue would be of interest. Second, Gly-L-Lys(Ac), a good analogue of a hypothetical natural R61 acceptor (see 1), was a poor acyl acceptor in experiments with $\mathbf{1 4}$ and the R61 DD-peptidase [considerably less effective than D-alanine and Gly-L-Ala, for example (29)]. This was taken to be an indication that the R61 enzyme, in vivo, may largely be a carboxypeptidase.

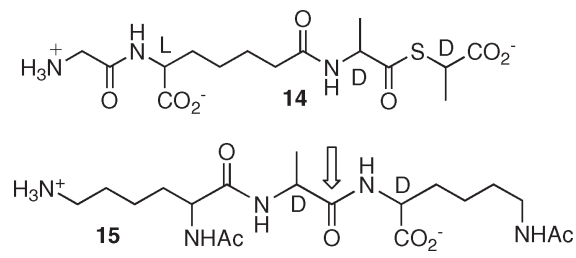

The converse result in the present case could therefore be interpreted to mean that the R39 DD-peptidase is a transpeptidase rather than a carboxypeptidase. Alternatively, and probably more likely in view of the above results, the R39 enzyme may predominantly be an endopeptidase. In cases where the stem peptide has the structure 5, this DD-endopeptidase reaction is of course formally also a DD-carboxypeptidase reaction although it differs in consequence since it leads to cleavage of the peptidoglycan cross-links rather than just clipping terminal D-alanine residues.

In view of the above results, the peptide $\mathbf{1 5}$ was designed as a useful "endopeptidase" substrate (anticipated cleavage site indicated). It contains the putative "natural" leaving group analogue, $N$ - $\varepsilon$-Ac-D-Lys, and has a simple ammonium ion at the side chain $\mathrm{N}$-terminus. The latter will probably decrease its reactivity as an acyl donor (compare $\mathbf{4}$ and $\mathbf{1 1}$ ), but it will also remove the ability of $\mathbf{1 5}$ to be an acyl acceptor $(N-\alpha$-AcL-Lys is a very poor acceptor, Table 3). Peptide $\mathbf{1 5}$, in fact, turned out to be a quite effective endopeptidase substrate of the R39 DD-peptidase (Table 2) although not as reactive as 4. ${ }^{1} \mathrm{H}$ NMR monitoring of the reaction of $\mathbf{1 5}$ with the R39 enzyme showed clean cleavage to $N$ - $\alpha$-Ac-L-Lys-D-Ala and $N$ - - -Ac-D-Lys, with no sign of intermediates. Studies with D-alanine as an alternative acceptor $(29,32)$ showed that deacylation was rate-determining under active site saturation conditions.

The data from the "transpeptidase" reactions of 7 thus show the preference of the R39 DD-peptidase for an extended acyl acceptor, as would be expected in both the transpeptidase and endopeptidase reactions of a natural substrate.

$p H-$ Rate Profiles. The $k_{\text {cat }} / K_{\mathrm{m}}$ and $k_{\text {cat }} \mathrm{pH}$-rate profiles for hydrolysis of 7, catalyzed by the R39 DD-peptidase, are shown in Figure 6. The former shows a bell-shaped profile with maximal activity at around $\mathrm{pH} 7.4$ and $\mathrm{p} K_{\mathrm{a}}$ values of 6.1 and 8.4. The $k_{\text {cat }}$ profile is quite different with a plateau at low $\mathrm{pH}\left(k_{\text {cat }} \approx 5 \mathrm{~s}^{-1}\right)$ and rising, apparently linearly ( $\log k_{\text {cat }}$ ), with $\mathrm{pH}$ (slope 1$)$ at $\mathrm{pH}>7$; a best fit of these data does not require an acid 

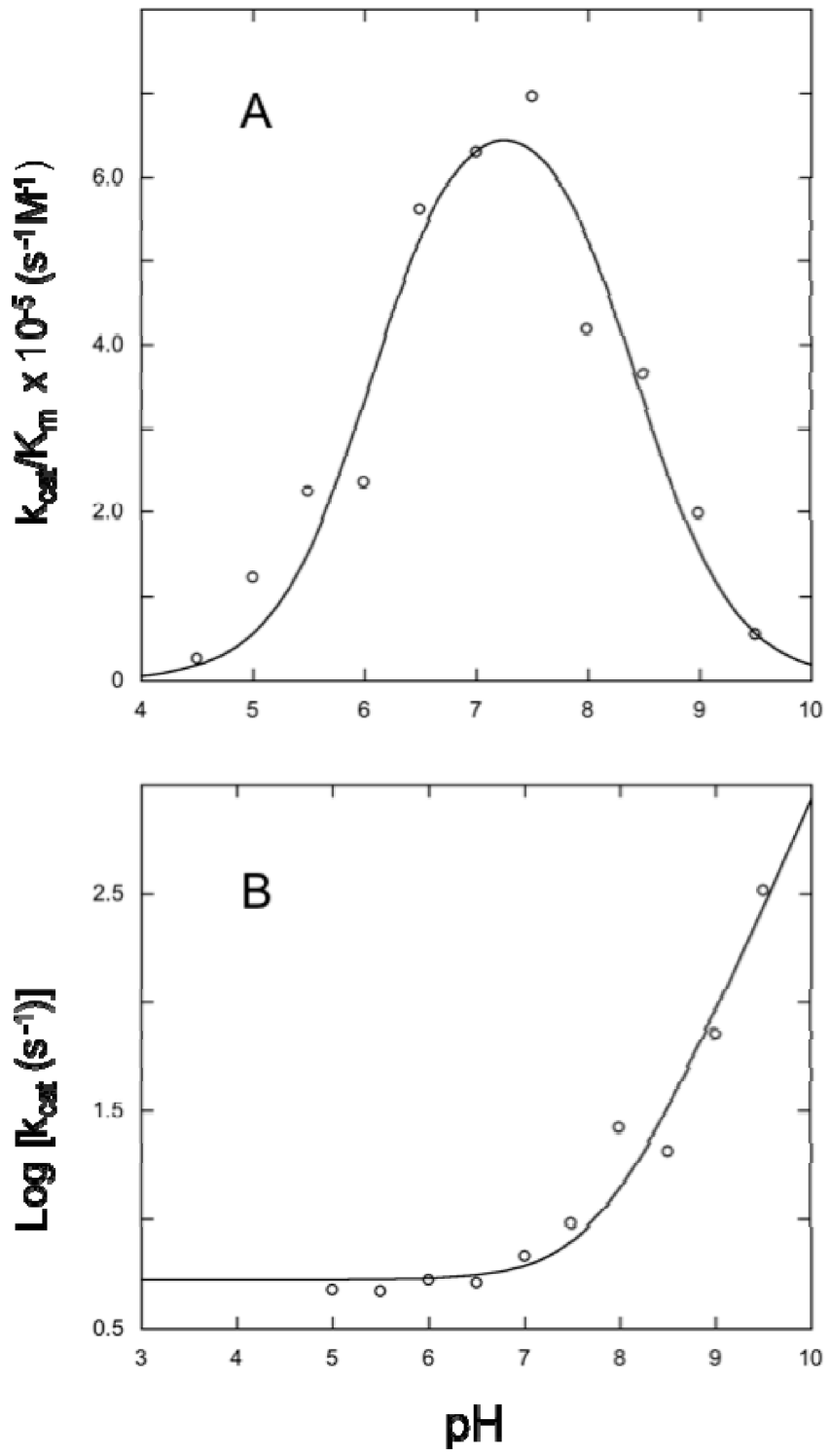

Figure 6: (A) pH-rate profile $\left(k_{\mathrm{cat}} / K_{\mathrm{m}}\right)$ for the reaction of 7 with the R39 DD-peptidase. The points are experimental, and the line represents the fit of the data to eq 1 (see text). (B) $\mathrm{pH}-$ rate profile (logarithmic) of $k_{\text {cat }}$ for reaction of 7 with the R39 DD-peptidase. The points are experimental, and the line represents the fit of the data to eq 2 (see text).

Table 4: $\mathrm{pH}$ Dependence of Second-Order Rate Constants for Reaction of Various Substrates and $\beta$-Lactams with the R39 DD-Peptidase ${ }^{a}$

\begin{tabular}{cccr}
\hline substrate & \multicolumn{1}{c}{$k_{2}\left(\mathrm{~s}^{-1} \mathrm{M}^{-1}\right)$} & $\mathrm{p} K_{\mathrm{a} 1}$ & \multicolumn{1}{c}{$\mathrm{p} K_{\mathrm{a} 2}$} \\
\hline $\mathbf{7}$ & $(7.3 \pm 0.7) \times 10^{5}$ & $6.08 \pm 0.16$ & $8.42 \pm 0.16$ \\
$\mathbf{1 1}$ & $(3.9 \pm 0.5) \times 10^{4}$ & $6.42 \pm 0.15$ & $8.18 \pm 0.33$ \\
$\mathbf{1 5}$ & $(4.7 \pm 0.5) \times 10^{4}$ & $6.56 \pm 0.11$ & $7.65 \pm 0.14$ \\
$\mathbf{1 6}$ & $(1.35 \pm 0.07) \times 10^{3}$ & $7.07 \pm 0.20$ & $10.86 \pm 0.11$ \\
$\mathbf{1 7}$ & $(3.6 \pm 0.1) \times 10^{2}$ & $5.78 \pm 0.09$ & $11.32 \pm 0.12$ \\
\hline
\end{tabular}

${ }^{a}$ Determined in mixed buffer.

dissociation above $\mathrm{pH} 7$ at less than 9.5, the highest $\mathrm{pH}$ for which data were obtained. Further perspective is provided by the $k_{\text {cat }} / K_{\mathrm{m}}$ profiles of the peptides $\mathbf{1 1}$ and $\mathbf{1 5}$ and the $\beta$-lactams cefotaxime (16) and 7-aminocephalosporanic acid (17) (Table 4). The $\beta$-lactams, at low concentration, acylate the enzyme in a second-order fashion. These second-order rate constants should be comparable to the $k_{\mathrm{cat}} / K_{\mathrm{m}}$ parameter for substrates. Unlike
Scheme 9

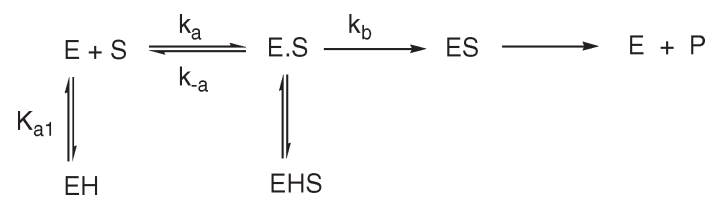

from substrates, however, the acyl-enzymes derived from $\beta$ lactams are inert to hydrolysis (25).<smiles>COCC1=C(C(=O)OC)N2C(=O)C(NC(=O)/C(=N\OC)c3csc(N)n3)CSC2C1</smiles>

16<smiles>CC1COC(=O)C(=O)C1=O</smiles>

17
In a simple three-step reaction sequence (Scheme 9), the $\mathrm{pH}$ dependence of $k_{\text {cat }} / K_{\mathrm{m}}$ should reflect the $\mathrm{p} K_{\mathrm{a}}(\mathrm{s})$ of free enzyme and free substrate $(33,34)$. The enzyme-related values should, therefore, be independent of the identity of the substrate. It is noticeable from Table 4, however, that the $\mathrm{p} K_{\mathrm{a} 1}$ (and $\mathrm{p} K_{\mathrm{a} 2}$ ) values do vary and well beyond experimental uncertainty. The most likely explanation for this would involve the substrates being "sticky" (35). If the acylation of the enzyme is represented by Scheme 9 , as in most simple cases, the observed $\mathrm{p} K_{\mathrm{a} 1}$ of $k_{\text {cat }} /$ $K_{\mathrm{m}}$ is given by eq $3(35) ; \mathrm{p} K_{\mathrm{al}}{ }^{\text {app }}$ will, therefore, be lower than $\mathrm{p} K_{\mathrm{a} 1}$ and particularly noticeably so when $k_{\mathrm{b}}>k_{-\mathrm{a}}$. It is therefore possible that the more specific substrates 7, 11, and $\mathbf{1 5}$ are stickier than the $\beta$-lactam cefotaxime, and thus $\mathrm{p} K_{\mathrm{a} 1} \geq 7.1$. Since $k_{\mathrm{b}}$ is likely to be larger for thioester 7 than the peptides $\mathbf{1 1}$ and $\mathbf{1 5}$, the lower apparent $\mathrm{p} K_{\mathrm{a} 1}$ for 7 is reasonable. The raising of $\mathrm{p} K_{\mathrm{a} 2}{ }^{\text {app }}$ for $\mathbf{1 5}, 11$, and 7 in a mirror image fashion can also be understood in terms of stickiness at $\mathrm{pH}>7$ and suggests that $\mathrm{p} K_{\mathrm{a} 2} \leq 7.6$, i.e., very close, perhaps, to $\mathrm{p} K_{\mathrm{a} 1}(26)$. Sticky protons may also lead to apparent $\mathrm{p} K_{\mathrm{a}}$ variation $(35,36)$.

$$
\mathrm{p} K_{\mathrm{a} 1}{ }^{\mathrm{app}}=\mathrm{p} K_{\mathrm{a} 1}-\log \left(1+k_{\mathrm{b}} / k_{-\mathrm{a}}\right)
$$

More striking in Table 4 is the low $\mathrm{p} K_{\mathrm{a} 1}$ for $\mathbf{1 7}$ (which was included to assess the effect of the $\beta$-lactam side chain) and the high $\mathrm{p} K_{\mathrm{a} 2}$ values for the cephalosporins. The low $\mathrm{p} K_{\mathrm{a} 1}$ for $\mathbf{1 7}$ does not reflect the $\mathrm{p} K_{\mathrm{a}}$ of the protonated 7-amino group of $\mathbf{1 7}$ [4.47 (37)] and must therefore represent the result of complex binding kinetics. The $\mathrm{p} K_{\mathrm{a} 2}$ values for $\mathbf{1 6}$ and $\mathbf{1 7}(>10)$ are intriguingly much higher than those from the substrate profiles. Interpretation of these $\mathrm{p} K_{\mathrm{a}} \mathrm{s}$ in terms of active site structure can only be rather speculative. The most obvious dissociable active site residues are the two conserved lysine residues, one from the SXXK active site motif (Lys 52 in the R39 sequence) and the second from the $\mathrm{KT}(\mathrm{S}) \mathrm{G}$ motif (Lys 410). It is possible that at least one of these residues, most likely, Lys 52 , has a low $\mathrm{p} K_{\mathrm{a}}$, corresponding to $\mathrm{p} K_{\mathrm{a} 1}$ and is required as a general base in catalysis $(9,16)$. Interpretation of $\mathrm{p} K_{\mathrm{a} 2}$ is more problematic, especially in view of the disparate values for substrates and $\beta$-lactams noted above. Although both peptide and $\beta$-lactam (but not thioester) hydrolysis probably require a general acid catalyst to assist (amine) leaving group departure, it seems unlikely from the $\mathrm{p} K_{\mathrm{a} 2}$ values that they employ the same one, if indeed the dissociation of this general acid is observed in the $\mathrm{pH}$ range covered (4.5-9.5). It seems more likely that the lower $\mathrm{p} K_{\mathrm{a} 2}$, 
Table 5: Solvent Deuterium Kinetic Isotope Effects

\begin{tabular}{ccc}
\hline substrate & ${ }^{\mathrm{D}} V / K$ & ${ }^{\mathrm{D}} V$ \\
\hline $\mathbf{7}$ & $2.0 \pm 0.4$ & $2.4 \pm 0.2$ \\
$\mathbf{1 5}$ & $2.8 \pm 0.3$ & $2.4 \pm 0.2$ \\
\hline
\end{tabular}

observed in peptide hydrolysis, reflects the dissociation of another residue, one not in direct contact with the substrate at the active site but which must be required for peptide and thioester hydrolysis and efficient departure of the leaving group. This residue may not be required for acylation of the enzyme by $\beta$-lactams where the higher $\mathrm{p} K_{\mathrm{a} 2}$ may reflect dissociation of Lys 410. Similar $\mathrm{pH}$ profiles have been obtained for a few other DDpeptidases $(38-41)$ and generally interpreted in terms of the $\mathrm{p} K_{\mathrm{a}} \mathrm{s}$ of the two lysines.

Interestingly different from the above profiles is that of Escherichia coli PBP5 as a catalyst of hydrolysis of $N, N^{\prime}$ diacetyl-L-lysyl-D-alanyl-D-alanine $(42,43)$ where maximal activity in both $k_{\text {cat }} / K_{\mathrm{m}}$ and $k_{\text {cat }}$ profiles occurs around a $\mathrm{pH}$ of 10 , with associated $\mathrm{p} K_{\mathrm{a}} \mathrm{s}$ of 9.1 and 10.8. These were interpreted in terms of dissociations of the two lysines. Both $k_{\text {cat }} / K_{\mathrm{m}}$ and $k_{\text {cat }}$ profiles, however, also show a small shoulder around $\mathrm{pH} 7$ (with a reported acid dissociation of $\mathrm{p} K_{\mathrm{a}} 6.1$ ), which may correspond to the activity maximum observed in the present work and in other cases (38-41). It might be noted that, conversely, a small rise at higher $\mathrm{pH}$ is clearly visible in the $k_{\text {cat }} / K_{\mathrm{m}}$ profile of $\mathbf{1 1}$ (not shown). The difference between the relative heights of these maxima, which is seen between the R39 (and other) DD-peptidases and E. coli PBP5, may reflect the existence of the latter predominantly in solution, as in the crystal (15), in a less active conformation; dissociation of a second lysine (or other functional group) at higher $\mathrm{pH}$ does, however, promote the reaction. Nonetheless, the reported activity of PBP5, even against $N, N^{\prime}$ diacetyl-L-Lys-D-Ala-D-Ala, is very low $\left[k_{\text {cat }} / K_{\mathrm{m}}\right.$ values around $1 \mathrm{~s}^{-1} \mathrm{M}^{-1}$ at $\mathrm{pH} 7$ and $11 \mathrm{~s}^{-1} \mathrm{M}^{-1}$ at $\mathrm{pH} 10$ (43)].

Solvent Deuterium Kinetic Isotope Effects. These were measured for the thioester $\mathbf{7}$ and the peptide $\mathbf{1 5}$ (rather than for $\mathbf{6}$, because of the complex kinetics of reaction of the latter; see above) and are shown in Table 5. The immediate conclusion is that proton transfer, likely arising from general acid/base catalysis, is present in the transition states for both acylation $(V / K)$ and deacylation $(V)$. Such catalysis does indeed appear in most mechanisms that have been proposed $(9,16)$. Values of ${ }^{\mathrm{D}} V$ are very similar to those previously determined for the Streptomyces R61 DD-peptidase (44), which were interpreted similarly. Strikingly different, however, are the values of ${ }^{\mathrm{D}} V / K$. For the R61 enzyme and for the structurally related class $A$ and, more particularly, class $\mathrm{C} \beta$-lactamases, which also catalyze the hydrolysis of acyclic thioesters, the ${ }^{\mathrm{D}} V / K$ solvent isotope effects are small and can be either normal or inverse $(0.8-1.2)(26,44)$. This has been ascribed to the presence of a low fractionation factor hydrogen in the free enzyme $(44,45)$, whose effect is offset by proton transfer during acylation. The ${ }^{\mathrm{D}} V / K$ values obtained here give no indication of such a hydrogen in the R39 enzyme active site. The large solvent kinetic isotope effects obtained speak only of general base catalysis, as noted above. The slightly lower value for the thioester suggests that transition states for both formation and breakdown of the tetrahedral intermediate of the acylation reaction contribute to the observed rate constant and kinetic isotope effect, of 7 at least, since general acid catalysis of breakdown of the intermediate from 7 , with a thiolate leaving group, is probably not required, unlike with the amine leaving group from the peptide $\mathbf{1 5}$ (46).

The significantly different ${ }^{\mathrm{D}} V / K$ values between the R39 DDpeptidase and the other enzymes mentioned above do correlate nicely with differences in active site structure. The R61 DDpeptidase, like class $\mathrm{C} \beta$-lactamases, has a Tyr/Lys hydrogenbonded couple at the active site, which may exist in zwitterionic form in the free enzyme. It has been proposed that the hydrogen involved in this hydrogen bond may be the low fractionation factor contributor to the isotope effect $(26,45)$. Similarly, the class A $\beta$-lactamases have a Glu/Lys couple that may contribute analogously. The tyrosine and glutamate residues at these $\beta$-lactamase active sites are thought to be required for efficient deacylation of acyl-enzymes derived from $\beta$-lactams (4). The DD-peptidases, in general, apart from low molecular mass class B enzymes, such as that from Streptomyces R61, do not have such functionality and thus, perhaps, do not have the characteristic low fractionation factor hydrogen; there is, nonetheless, quite a lot of intraprotein hydrogen bonding of the active site components in DD-peptidases in general, including the R39 enzyme (19).

Conclusions. Previous studies of the substrate specificity of the R39 DD-peptidase suggested great specificity in the acyl donor for a free N-terminal D-amino acid, as in the peptide 4 (11). The $\mathrm{D}-\alpha$-aminopimelyl $\mathrm{N}$-terminus of $\mathbf{4}$ obviously closely resembles the side chain $\mathrm{N}$-terminus of the monomeric stem peptide $\mathbf{5}$. The above-referenced paper also showed that the $N$-acyl-L-alanylD-isoglutamyl "north fork" of the stem peptide did not convey reactivity to model substrates such as $\mathbf{3}$ and therefore probably did not have a specific binding site on the enzyme. The experiments described in this paper confirm the specificity of the R39 DD-peptidase for a free D-amino acid terminus in the acyl donor through the reactivity of $\mathbf{6 , 7 , 9}$, and $\mathbf{1 0}$ (Table 2). Also striking in this regard is the poor (not observed) reactivity of 9 as a carboxypeptidase substrate in contrast to its high activity as an endopeptidase substrate. A considerable part of this difference must come from the acylation of the N-terminus in $\mathbf{6}$ when considered as a carboxypeptidase substrate; the additional acyl group would probably interact unfavorably with Trp 139 and Asp 142 in the important side chain N-terminal specificity site (15).

The complex reactions observed for $\mathbf{6}$ (Scheme 6) (and their likely presence with 4) showed that the R39 DD-peptidase can act as a transpeptidase and endopeptidase. This result is indicated by the formation and breakdown of the condensation products 9 and $\mathbf{1 0}$ in addition to formation of the expected carboxypeptidase product 8. Finally, the much higher $k_{\text {cat }} / K_{\mathrm{m}}$ value for the extended peptide 9 (and, most likely, for its analogue derived from 4 ) in the endopeptidase reaction than that for either $\mathbf{6}$ (carboxypeptidase reaction) or $\mathbf{1 0}$ (endopeptidase reaction) suggests that the highest activity of the R39 enzyme would be as an endopeptidase cleaving a peptidoglycan polymer adjacent to a free side chain N-terminus (Figure 7). This conclusion is supported by the effectiveness of extended nucleophiles, $N$ - $\varepsilon$-acetylD-lysine and, particularly, 6 itself against the acyl-enzyme generated from 6 or 7 (Table 3 ). The lesser effectiveness of D-Lys $(N$-AcL-Ala-D-iGln) as a nucleophile suggests that the presence of the "north fork" in a substrate leaving group (endopeptidase reaction) confers little benefit. The much greater effectiveness of the extended nucleophiles mentioned above than D-alanine (Table 3) indicates that the R39 DD-peptidase is probably a more effective endopeptidase than carboxypeptidase. This conclusion agrees with most current views of the in vivo role of LMM class C 

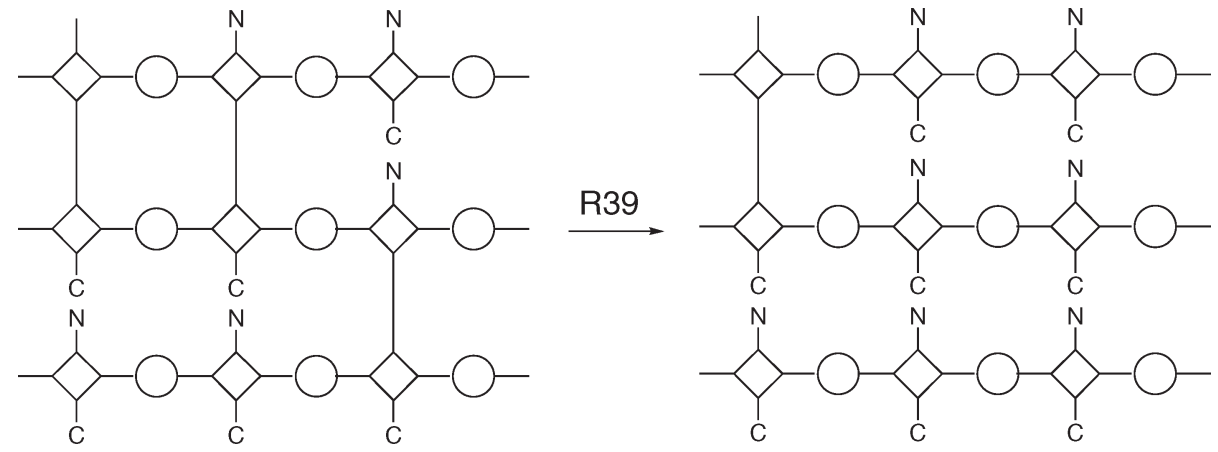

FIgURE 7: Endopeptidase activity of the R39 DD-peptidase. Circles represent $N$-acetylglucosamine, squares $N$-acetylmuramic acid, and vertical lines peptide cross-links. When not cross-linked, the peptides have free side chain $\mathrm{N}$ - and $\mathrm{C}$-termini, one of each per $N$-acetylmuramic acid. The enzyme cleaves cross-links that have a free side chain N-terminus on the acyl side.

DD-peptidases (2), including E. coli PBP4, for example (20, 46). Recently, Duez et al. have demonstrated endopeptidase activity against a small peptidoglycan-mimetic peptide in another such enzyme, Bacillus subtilis PBP 4a (47). An endopeptidase substrate $\mathbf{1 5}$, which is not susceptible to the carboxypeptidase or transpeptidase (here defined as beginning by D-alanine displacement) reactions, has been described.

The $\mathrm{pH}$ dependence of $k_{\text {cat }} / K_{\mathrm{m}}$ for the carboxypeptidase reactions of 7, 11, and $\mathbf{1 5}$ with the R39 DD-peptidase gave evidence of complex proton-dissociation schemes and/or sticky substrates or protons. The $\mathrm{pH}$ dependence of reaction of the $\beta$-lactams 16 and 17 with the enzyme may also reflect complicated phenomena since they do not mimic the $\mathrm{pH}$ dependence of the peptide substrates (Table 4). The reactions of peptides and $\beta$-lactams may occur at active sites with locally different protein conformations. Finally, the solvent kinetic deuterium isotope effects ${ }^{\mathrm{D}} V / K$ and ${ }^{\mathrm{D}} V$ indicate straightforward general acid/base catalysis in both enzyme acylation and deacylation steps of turnover.

The methods employed above may, in principle, be applied to any bacterial DD-peptidase in order to better define its substrate specificity.

\section{SUPPORTING INFORMATION AVAILABLE}

Details of the syntheses of the substrates 6 and 7 . This material is available free of charge via the Internet at http://pubs.acs.org.

\section{REFERENCES}

1. Vollmer, W., and Bertsche, U. (2007) Murein (peptidoglycan) structure, architecture and biosynthesis in Escherichia coli. Biochim. Biophys. Acta 1778, 1714-1734.

2. Sauvage, E., Kerff, F., Terrak, M., Ayala, J. A., and Charlier, P. (2008) The penicillin-binding proteins: structure and role in peptidoglycan biosynthesis. FEMS Microbiol. Rev. 32, 234-258.

3. Waxman, D. J., and Strominger, J. L. (1983) Penicillin-binding proteins and the mechanism of action of $\beta$-lactam antibiotics. Аnnu. Rev. Biochem. 52, 825-869.

4. Pratt, R. F. (2002) Functional evolution of the serine $\beta$-lactamase active site. J. Chem. Soc. Perkin 2, 851-861.

5. Payne, D. J., Gwynn, M. N., Holmes, D. J., and Pompliano, D. L. (2007) Drugs for bad bugs: confronting the challenges of antibacterial discovery. Nat. Rev. Drug Discov. 6, 29-40.

6. Boucher, H. W., Talbot, G. H., Bradley, J. S., Edwards, T. E., Gilbert, D., Rice, L. B., Scheld, M., Spellberg, B., and Bartlett, J. (2009) Bad bugs, no drugs: no ESKAPE! An update from the Infectious Diseases Society of America. Clin. Infect. Dis. 48, 1-12.

7. Ghuysen, J.-M. (1991) Serine $\beta$-lactamases and penicillin-binding proteins. Annu. Rev. Microbiol. 45, 37-67.

8. Goffin, C., and Ghuysen, J.-M. (1998) Multimodular penicillinbinding proteins: an enigmatic family of orthologs and paralogs. Microbiol. Mol. Biol. Rev. 62, 1079-1093.
9. Pratt, R. F. (2008) Substrate specificity of bacterial DD-peptidases (penicillin-binding proteins). Cell. Mol. Life Sci. 65, 2138-2155.

10. Anderson, J. W., and Pratt, R. F. (2000) Dipeptide binding to the extended active site of the Streptomyces R61 D-alanyl-D-alanine peptidase: the path to a specific substrate. Biochemistry 39, 1220012209.

11. Anderson, J. W., Adediran, S. A., Charlier, P., Nguyen-Distèche, M., Frère, J.-M., Nicholas, R. A., and Pratt, R. F. (2003) On the substrate specificity of bacterial DD-peptidases: evidence from two series of peptidoglycan-mimetic peptides. Biochem. J. 373, 949-955.

12. McDonough, M. A., Anderson, J. W., Silvaggi, N. R., Pratt, R. F., Knox, J. R., and Kelly, J. A. (2002) Structures of two kinetic intermediates reveal species specificity of penicillin-binding proteins. J. Mol. Biol. 322, 111-122.

13. Silvaggi, N. R., Anderson, J. W., Brinsmade, S. R., Pratt, R. F., and Kelly, J. A. (2003) The crystal structure of a phosphonate-inhibited D-Ala-D-Ala peptidase reveals an analogue of a tetrahedral transition state. Biochemistry 42, 1199-1208.

14. Silvaggi, N. R., Josephine, H. R., Kuzin, A. P., Nagarajan, R., Pratt, R. F., and Kelly, J. A. (2005) Crystal structures of complexes between the R61 DD-peptidase and peptidoglycan-mimetic $\beta$-lactams: a noncovalent complex with a "perfect penicillin. J. Mol. Biol. 345, 521533.

15. Sauvage, E., Powell, A. J., Heilemann, J., Josephine, H. R., Charlier, P., Davies, C., and Pratt, R. F. (2008) Crystal structures of complexes of bacterial DD-peptidases with peptidoglycan-mimetic ligands; the substrate specificity puzzle. J. Mol. Biol. 381, 383-393.

16. Dzhekieva, L., Rocaboy, M., Kerff, F., Charlier, P., Sauvage, E., and Pratt, R. F. (2010) Crystal structure of a complex between the Actinomadura R39 DD-peptidase and a peptidoglycan-mimetic boronate inhibitor: interpretation of a transition state analogue in terms of catalytic mechanism. Biochemistry 49, 6411-6419.

17. Ghuysen, J.-M., Frère, J.-M., Leyh-Bouille, M., Coyette, J., Dusart, J., and Nguyen-Distèche, M. (1977) Use of model enzymes in determination of the mode of action of penicillins and $\Delta 3$-cephalosporins. Annu. Rev. Biochem. 48, 73-101.

18. Zhao, G.-H., Duez, C., LePage, S., Forceille, C., Rhazi, N., Klein, D., Ghuysen, J.-M., and Frère, J.-M. (1997) Site-directed mutagenesis of the Actinomadura R39 DD-peptidase. Biochem. J. 327, 377-381.

19. Sauvage, E., Herman, R., Petrella, S., Duez, C., Bouillenne, F., Frère, J.-M., and Charlier, P. (2005) Crystal structure of the Actinomadura R39 DD-peptidase reveals new domains in penicillin-binding proteins. J. Biol. Chem. 280, 31249-31256.

20. Granier, B., Duez, C., Lepange, S., Englebert, S., Dusart, J., Dideberg, O., Van Beeumen, J., Frère, J.-M., and Ghuysen, J.-M. (1992) Primary and predicted secondary structures of the Actinomadura R39 extracellular DD-peptidase, a penicillin-binding protein (PBP) related to Escherichia coli PBP4. Biochem. J. 282, 781-788.

21. Nagarajan, R., and Pratt, R. F. (2004) Synthesis and evaluation of new substrate analogues of Streptomyces R61 DD-peptidase: dissection of a specific ligand. J. Org. Chem. 69, 7472-7478.

22. Johnson, K. A., Simpson, Z. B., and Blom, T. (2009) A new computer program for dynamic simulations and fitting of kinetic data. Anal. Biochem. 387, 20-29.

23. Kuzmic, P. (1996) Program DYNAFIT for the analysis of enzyme kinetic data: application to HIV proteinase. Anal. Biochem. 237, 260273.

24. Frére, J.-M., Leyh-Bouille, M., Ghuysen, J.-M., Nieto, M., and Perkins, H. R. (1976) Exocellular DD-carboxypeptidase-transpeptidases from Streptomyces. Methods Enzymol. 45, 610-636. 
25. Fuad, N., Frére, J.-M., Ghuysen, J.-M., Duez, C., and Iwatsubo, M. (1974) Mode of interaction between $\beta$-lactam antibiotics and the exocellular DD-carboxypeptidase-transpeptidase from Streptomyces R39. Biochem. J. 155, 623-629.

26. Adediran, S. A., Deraniyagala, S. A., Xu, Y., and Pratt, R. F. (1996) $\beta$-Secondary and solvent deuterium kinetic isotope effects on $\beta$-lactamase catalysis. Biochemistry 35, 3604-3613.

27. Stein, R. L. (1983) Catalysis by human leukocyte elastase: substrate structural operation of the charge relay system. J. Am. Chem. Soc. 105, 5111-5116.

28. Adediran, S. A., Kumar, I., and Pratt, R. F. (2006) Deacylation transition states of a bacterial DD-peptidase. Biochemistry 45, 13074 13082.

29. Kumar, I., and Pratt, R. F. (2005) Transpeptidation reactions of a specific substrate catalyzed by the Streptomyces R61 DD-peptidase: characterization of a chromogenic substrate and acyl acceptor design. Biochemistry 30, 9971-9979.

30. Adam, M., Damblon, C., Plaitin, B., Christiaens, L., and Frère, J.-M. (1990) Chromogenic depsipeptide substrates for $\beta$-lactamases and penicillin-sensitive DD-peptidases. Biochem. J. 270, 525-529.

31. Jamin, M., Adam, M., Damblon, C., Christiaens, L., and Frère, J.-M. (1991) Accumulation of acyl-enzymes in DD-peptidase-catalyzed reactions with analogues of peptide substrates. Biochem. J. 280, 499-506.

32. Kumar, I., and Pratt, R. F. (2005) Transpeptidation reactions of a specific substrate catalyzed by the Streptomyces R61 DD-peptidase: the structural basis of acyl acceptor specificity. Biochemistry 44, 99619970.

33. Peller, L., and Alberty, R. A. (1959) Multiple intermediates in steady state enzyme kinetics. I. The mechanism involving a single substrate and product. J. Am. Chem. Soc. 81, 5907-5914.

34. Knowles, J. R. (1976) The intrinsic pKa values of functional groups in enzymes: improper deductions from the $\mathrm{pH}$-dependence of steady state parameters. CRC Crit. Rev. Biochem. 4, 165-173.

35. Cleland, W. W. (1977) Determining the chemical mechanisms of enzyme-catalyzed reactions by kinetics studies. Adv. Enzymol. 45, 273-387.

36. Hardy, L. W., Nishida, C. H., and Kirsch, J. F. (1984) Anomalous pH dependence of the reactions of carbenicillin and sulbenicillin with Bacillus cereus $\beta$-lactamase I. Influence of the $\alpha$-substituent charge on the kinetic parameters. Biochemistry 23, 1288-1294.
37. Kóczián, K., Szakács, Z., Kökösi, J., and Noszál, B. (2007) Sitespecific protonation micro equilibria of penicillin and cephalosporin beta-lactam core molecules. Eur. J. Pharm. Sci. 32, 1-7.

38. Varetto, L., Frère, J.-M., Nguyen-Distèche, M., Ghuysen, J.-M., and Houssier, C. (1987) The $\mathrm{pH}$ dependence of the active site serine DDpeptidase of Streptomyces R61. Eur. J. Biochem. 162, 525-531.

39. Stevanova, M. E., Tomberg, J., Olesky, M., Höltje, J.-V., Gutheil, W. G., and Nicholas, R. A. (2003) Neisseria gonorrhoeae penicillinbinding protein 3 exhibits exceptionally high carboxypeptidase and $\beta$-lactam binding activities. Biochemistry 42, 14614-14625.

40. Stefanova, M. E., Tomberg, J., Davies, C., Nicholas, R. A., and Gutheil, W. G. (2004) Overexpression and enzymatic characterization of Neisseria gonorrhoeae penicillin-binding protein 4. Eur. J. Biochem. $271,23-32$.

41. Thomas, B., Wang, Y., and Stein, R. L. (2001) Kinetic and mechanistic studies of penicillin-binding protein $2 \mathrm{x}$ from Streptococcus pneumoniae. Biochemistry 40, 15811-15823.

42. Stefanova, M. E., Davies, C., Nicholas, R. A., and Gutheil, W. G. (2009) $\mathrm{pH}$, inhibitor and substrate specificity studies on Escherichia coli penicillin-binding protein 5. Biochim. Biophys. Acta 1597, 292300.

43. Zhang, W., Shi, Q., Meroueh, S. O., Vakulenko, S. B., and Mobashery, S. (2007) Catalytic mechanism of penicillin-binding protein 5 of Escherichia coli. Biochemistry 46, 10113-10121.

44. Adediran, S. A., and Pratt, R. F. (1999) $\beta$-Secondary and solvent deuterium isotope effects on catalysis by the Streptomyces R61 DD-peptidase: comparisons with a structurally similar class C $\beta$-lactamase. Biochemistry 38, 1469-1477.

45. Page, M. I., Vilanova, B., and Layland, N. J. (1995) pH dependence of and kinetic solvent isotope effects on the methanolysis and hydrolysis of $\beta$-lactams catalyzed by class C $\beta$-lactamase. J. Am. Chem. Soc. 117, $12092-12095$.

46. Korat, B., Mottl, H., and Keck, W. (1991) Penicillin-binding protein 4 of Escherichia coli: molecular cloning of the dac B gene, controlled overexpression, and alterations in murein composition. Mol. Microbiol. 5, 675-684.

47. Duez, C., Zervosen, A., Teller, N., Melkonian, R., Banzubazé, E., Bouillenne, F., Luxen, A., and Frère, J.-M. (2009) Characterization of the proteins encoded by the Bacillus subtilis yoxA-dacC operon. FEMS Microbiol. Lett. 300, 42-47. 